\title{
Optimization of Lignin Recovery from the Pre-Hydrolysate of Kraft-Based Dissolving Pulp Production Processes
}

\author{
Adil Mazar ${ }^{1,2, *}$, Naceur Jemaa ${ }^{2}$, Waleed Wafa Al Dajani ${ }^{2}$, Mariya Marinova ${ }^{3}$ (D) and Michel Perrier $^{1}$ \\ 1 Chemical Engineering Department, Ecole Polytechnique de Montreal, Montreal, QC H3T 1J4, Canada; \\ michel.perrier@polymtl.ca \\ 2 FPInnovations, Pulp, Paper and Bioproducts, 570 St John Blvd, Pointe Claire, QC H9R 3J9, Canada; \\ Naceur.jemaa@fpinnovations.ca (N.J.); Waleed.WafaAlDajani@fpinnovations.ca (W.W.A.D.) \\ 3 Chemistry and Chemical Engineering, Royal Military College of Canada, Kingston, ON K7K 7B4, Canada; \\ Mariya.Marinova@rmc-cmr.ca \\ * Correspondence: adil_drisse@hotmail.com or adil.mazar@fpinnovations.ca or adil.mazar@polymtl.ca
}

Citation: Mazar, A.; Jemaa, N.;

Wafa Al Dajani, W.; Marinova, M.; Perrier, M. Optimization of Lignin Recovery from the Pre-Hydrolysate of Kraft-Based Dissolving Pulp Production Processes. Appl. Sci. 2021, 11, 454. https://doi.org/ 10.3390/app11010454

Received: 15 December 2020 Accepted: 29 December 2020 Published: 5 January 2021

Publisher's Note: MDPI stays neutral with regard to jurisdictional clai$\mathrm{ms}$ in published maps and institutional affiliations.

Copyright: (C) 2021 by the authors. Licensee MDPI, Basel, Switzerland. This article is an open access article distributed under the terms and conditions of the Creative Commons Attribution (CC BY) license (https:// creativecommons.org/licenses/by/ $4.0 /)$.
Abstract: A pre-hydrolysate is an aqueous stream obtained during the production of hardwood kraft dissolving pulp. It is rich in sugars and contains dissolved organic matters. The purpose of this study is to investigate the optimization of lignin recovery from wood pre-hydrolysates and to characterize the extracted lignin. The optimal conditions for lignin extraction have been determined to be (a) a filtration temperature of $40{ }^{\circ} \mathrm{C}$, (b) a sulfuric acid concentration of $8.5 \mathrm{~kg} \cdot \mathrm{m}^{-3}$, and (c) a coagulation time of $180 \mathrm{~min}$. Using these conditions, high filtration rates have been obtained and the extracted lignin has a low content of impurities (8.3\%), a low molecular weight (1270 Da), and a very low polydispersity $(\mathrm{Mw} / \mathrm{Mn}=1.22)$. Compared to kraft lignin, the pre-hydrolysate lignin has a much lower molecular weight and could be a potential candidate for niche applications. A high lignin recovery rate is possible ( $52 \%$ of the total lignin content in the pre-hydrolysate).

Keywords: lignin recovery; pre-hydrolysate; kraft dissolving pulp; lignin extraction

\section{Introduction}

During the last decade, there has been great interest in converting some hardwood kraft pulp mills to dissolving pulp (DP) operations (Figure 1). It has been reported that about 14 pulp mills have announced an increase in DP production or conversion from kraft to DP [1]. In kraft dissolving pulp mills, a step of pre-hydrolysis (using steam or hot water) is required to remove a significant part of hemicelluloses and lignin in order to produce purer cellulose pulp during subsequent steps. By subjecting wood chips to hot water treatment at about $170{ }^{\circ} \mathrm{C}$ and high pressure, the hemicelluloses are hydrolyzed to sugar oligomers and monomers. As a result, the hemicelluloses and part of the lignin present in wood chips are released into solution to form the pre-hydrolysate. This solution is then mixed with black liquor generated at the end of the cooking process. Black liquor has a high calorific value; it is sent to the recovery boilers for burning to produce energy and steam and to recycle chemicals used throughout the process to meet the internal needs of the plant. This high calorific value of black liquor is mainly due to the presence of lignin. The excess lignin can be extracted from black liquor using various techniques, namely acid precipitation, ultrafiltration, and use of organic solvents.

It is well known that most kraft pulp and paper mills in North America have recovery boilers with limited capacity [2,3]. To increase pulp production, either the capacity of the boiler should be increased or a new boiler must be purchased and installed. The latter option would be very expensive for a pulp mill. One less expensive option would be to reduce the load of the boilers by extracting a portion of the lignin from black liquor [4-6] or by extracting and valorizing the pre-hydrolysate. 


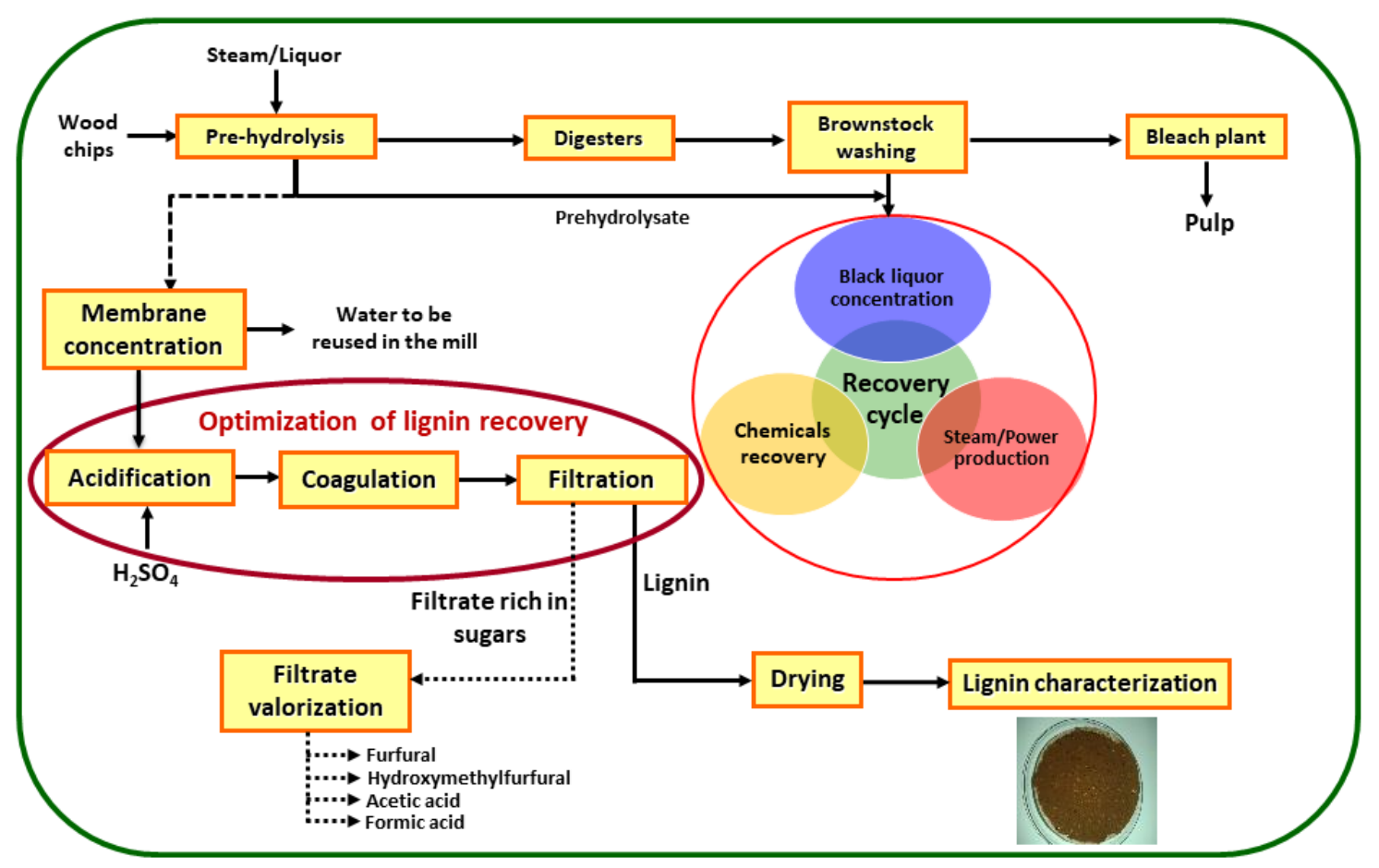

Figure 1. Pre-hydrolysate valorization options at a kraft dissolving pulp mill.

The pre-hydrolysate generated during the Kraft-based (PHK) dissolving pulp process can be a potential source for the production of biochemicals. Organic components such as lignin, monomeric and oligomeric sugars, and furfural and organic acids are present in the pre-hydrolysate and can be used to produce high value-added products. Several studies have been conducted on pre-hydrolysate valorization such as furfural production from prehydrolysate [7-10], furfural production from a pre-hydrolysate generated using $\mathrm{SO}_{2}$ [11], lignin removal by acidification [12], acidification and flocculation [13,14], surfactant and calcium oxide [15] or laccase treatments [16,17], as well as lignin recovery using membrane technology [18] and pre-hydrolysate detoxification [19]. However, the focus of all these studies was the valorization of hemicelluloses and organic acids to produce biochemicals and biofuels such as furfural, bio-ethanol, bio-butanol, acetic acid, formic acid, and succinic acid. Lignin in the pre-hydrolysate is considered a fermentation inhibitor and is removed prior to the conversion of sugars to biochemicals $[13,15,19]$. To date, very few works have been done on the extraction and characterization of lignin from wood pre-hydrolysate. In addition, no studies have been done on its recovery from the pre-hydrolysate. Unlike other types of lignin (kraft, lignosulphonates, and organosolv), this lignin has never been exposed to chemicals. Thus, its purity as well as chemical and physical properties are expected to be different from other lignins. However, it has not yet attracted attention from researchers. Numerous studies have been conducted to extract lignin from black liquor and various applications have been discussed in the literature such as the use of kraft lignin in rigid polyurethane foams [20], in flexible polyurethane foams [21], in phenol formaldehyde resins [22], and in activated carbon [23] as well as the use of lignin as an antioxidant and antibacterial [24]. Therefore, the recovery and characterization of lignin from the pre-hydrolysate will provide valuable information about its potential use and commercial applications. Figure 1 presents a simplified diagram of a kraft dissolving pulp mill with an approach to valorizing the pre-hydrolysate.

Shi et al. [13] published a study on the development of a new process by combining acidification and treatment with polyethylene oxide (PEO) to improve the extraction of lignin. The idea was to form lignin/PEO complexes which are easy to separate from the solution. With this technique, it was possible to extract more than $22 \%$ of lignin compared to only $3.8 \%$ when acid precipitation was used (at $\mathrm{pH}=2)$. 
Shi et al. [15] also studied the extraction of lignin from pre-hydrolysate using overliming treatment $(\mathrm{CaO})$ and/or surfactant molecules. The results showed that the highest extraction of lignin $(17 \%)$ was achieved by using dodecyltrimethylammonium chloride (DTAC) with an optimal ratio DTAC/pre-hydrolysate of $0.3 \%$. In addition, over-liming resulted in the extraction of $36 \%$ lignin and $23 \%$ hemicelluloses. The effect of the sequence/order of the two treatments on the lignin extraction rate was also studied. Overliming followed by treatment with DTAC was more effective than treatment with DTAC followed by over-liming. In the first case, a yield of $44 \%$ lignin removal and $27 \%$ hemicelluloses loss was obtained. In another study, Shi et al. [25] combined PEO and aluminum polychloride (PAC); $46 \%$ of lignin was extracted.

Chen et al. [26] tested several methods of lignin extraction from the pre-hydrolysate. Extractions of $27 \%, 52 \%, 36 \%$, and $25 \%$ were obtained using (1) precipitation at $\mathrm{pH}=2$, (2) ethanol, (3) polyDADMAC, and (4) PAC (aluminum polychloride), respectively. The corresponding sugar losses were $38 \%, 38 \%, 39 \%$, and $1.7 \%$, respectively.

The results obtained by Yasarla and Ramarao [14] were different since they were able to extract a higher amount of lignin $(70 \%)$ using polyDADMAC. However, polyDADMAC was not selective for lignin, since it resulted in 37\% and 38\% losses of sugars and acetic acid, respectively.

As previously reported by Mazar et al. [18], these techniques are still far from being optimal for recovering lignin from the pre-hydrolysate. In fact, they do not take into consideration a subsequent step that is needed for the recovery and the valorization of lignin. The only objective of these studies was to remove (and not to recover) lignin because it was considered a fermentation inhibitor. Therefore, it had to be separated before utilization of hemicelluloses (these techniques can be considered as detoxification steps). In addition, significant losses of hemicelluloses were observed in most of these techniques.

The objective of this study is to maximize the quantity of recovered lignin and to enhance its quality by determining the best conditions for the precipitation, coagulation, and filtration steps. To the best of our knowledge, this is the first study conducted to investigate the optimization of lignin recovery from a DP pulp mill pre-hydrolysate using the acidification method.

\section{Materials and Methods}

\subsection{Raw Materials}

The wood chips used in this study were a mixture of maple $(65 \mathrm{wt} \%)$ and aspen (35\% wt $\%$ ) obtained from 30-year-old trees (without bark). They were provided by a Canadian kraft dissolving pulp mill. The chips were screened on a disc screen using a thickness fraction between 2 and $8 \mathrm{~mm}$. The mass fractions of their solid contents were $60.5 \%$ and $37.3 \%$ for maple and aspen, respectively. In order to extract hemicelluloses from wood chips, the chips were subjected to a two-step treatment. The first step consisted of placing the chips in a $56 \mathrm{~L}$-digester and then purging them three times with steam to remove air. Each time, the treatment lasted for three minutes under a pressure of 138 $\mathrm{kPa}$. During the second step (the pre-hydrolysis), an initial water-to-wood ratio of 3:1 was employed. The pre-hydrolysis stage was carried out at a temperature of $170{ }^{\circ} \mathrm{C}$ for $90 \mathrm{~min}$ (typical conditions used usually in industrial level). About $15 \mathrm{dm}^{3}$ of pre-hydrolysate was produced per batch. A typical composition of the pre-hydrolysate is presented in Table 1.

\subsection{Pre-Hydrolysate Concentration}

In order to recover lignin from the pre-hydrolysate, a concentration step was done prior to the acidic precipitation. All concentration experiments were carried out under a temperature of $60^{\circ} \mathrm{C}$, a pressure of 30 bars, and a concentration factor (CF) of 5 (also called volume reduction factor (VRF)). 
Table 1. Composition of the pre-hydrolysate used in this work.

\begin{tabular}{cc}
\hline Species & Value \\
\hline Phenolics, $\mathrm{kg} \cdot \mathrm{m}^{-3}$ & 2.1 \\
Furfural, $\mathrm{kg} \cdot \mathrm{m}^{-3}$ & 0.6 \\
Solid, $\%(\mathrm{w} / \mathrm{w})$ & 0.1 \\
Total lignin, $\mathrm{kg} \cdot \mathrm{m}^{-3}$ & 4.3 \\
Acetic acid, $\mathrm{kg} \cdot \mathrm{m}^{-3}$ & 7.6 \\
Formic acid, $\mathrm{kg} \cdot \mathrm{m}^{-3}$ & 3.4 \\
Total sugars, $\mathrm{kg} \cdot \mathrm{m}^{-3}$ & 0.5 \\
Total monomeric sugars, $\mathrm{kg} \cdot \mathrm{m}^{-3}$ & 29 \\
Total oligomeric sugars, $\mathrm{kg} \cdot \mathrm{m}^{-3}$ & 5 \\
$\mathrm{pH}$ & 24 \\
\hline
\end{tabular}

The filtration experiments were conducted using a stainless-steel membrane module from Koch Membranes that contained a flat membrane with an effective surface of $28 \mathrm{~cm}^{2}$. The membrane system consisted of a pump (capacity of $1.8 \mathrm{dm}^{3} \cdot \mathrm{min}^{-1}$ ), a valve for adjusting the applied pressure, and a filtration module (max hold up volume is $500 \mathrm{~cm}^{3}$, max operating pressure is 35 bars, and max operating temperature is $90^{\circ} \mathrm{C}$ ).

\subsection{Lignin Recovery Optimization}

A pre-hydrolysate solution having the composition shown in Table 1 and containing about $7.6 \mathrm{~kg} \cdot \mathrm{m}^{-3}$ of total lignin was passed through a 1000-MW cutoff membrane and concentrated by a factor of 5 . In the concentrate, the total solid content increased from about $4.3 \%$ to about $16 \%$. The concentrate of this step was acidified by adding sulfuric acid ( 3 mole $\cdot \mathrm{dm}^{-3}$ ). The solution was left to coagulate for about $60-180 \mathrm{~min}$ at $73^{\circ} \mathrm{C}$ to allow lignin particles to agglomerate. After the coagulation-precipitation step, the lignin was separated from the liquid by a simple filtration.

For all the precipitation experiments, the membrane concentrates were heated to $73{ }^{\circ} \mathrm{C}$. The effect of parameters such as sulfuric acid concentration, filtration temperature, and coagulation time on the filtration flux and the amounts of recovered lignin, lignin purity, lignin molecular weight, and molecular weight distribution were studied in this work. Four final sulfuric acid concentrations were tested in this study $\left(0,5.7,8.5\right.$, and $\left.14 \mathrm{~kg} \cdot \mathrm{m}^{-3}\right)$ using a sulfuric acid solution with an initial concentration of 3 mole $\cdot \mathrm{dm}^{-3}$. Three membrane filtration temperatures were tested in the current study $\left(40,45\right.$, and $\left.50^{\circ} \mathrm{C}\right)$. The coagulation time varied between 60 and $180 \mathrm{~min}$.

To have an idea about the quality of the pre-hydrolysate lignin obtained (PHL lignin), its properties were compared to those of kraft softwood lignin (KSW lignin) and kraft hardwood lignin (KHW lignin). The KSW and KHW lignins were produced at FPInnovations using the LignoForce ${ }^{\mathrm{TM}}$ process.

\subsection{Chemical Analyses}

\subsubsection{Insoluble Lignin}

To determine the amount of insoluble lignin in each fraction, two $5 \mathrm{~cm}^{3}$ samples were subjected to acid hydrolysis with sulfuric acid. The final concentrations of sulfuric acid in the samples were adjusted to $2 \%$ and $4 \%$. The hydrolysis was conducted in a steam autoclave at a temperature of $121^{\circ} \mathrm{C}$ for one hour (NREL Technical Report: NREL/TP-51042618). The amount of solid residue after hydrolysis was determined gravimetrically by simple filtration using glass microfiber filters (Whatman, 934-AHTM, diameter $70 \mathrm{~mm}$ ) and expressed as acid-insoluble lignin.

\subsubsection{Soluble Lignin}

The lignin content was determined using a UV-visible spectrophotometer. The absorbance of the filtrate after acid hydrolysis was measured at a wavelength of $205 \mathrm{~nm}$. 
When needed, the samples were diluted with deionized water to obtain a final absorbance between 0.2 and 0.8 .

\subsubsection{Monomeric Sugar Content}

The monomeric sugars were determined by an ion chromatography with a Pulse Amperometric detector. A Dionex Ion Chromatograph (IC) equipped with ED-50 detector and a CarboPac PA1 column using distilled water as a mobile phase at a flow rate of $1.0 \mathrm{~cm}^{3} \cdot \mathrm{min}^{-1}$ and oven operating at ambient temperature was used to separate the sugars. The order of elution is arabinose, galactose, glucose, xylose, and mannose. Deoxy-Dglucose was used as an internal standard. A solution of $0.5 \mathrm{~mol} . \mathrm{dm}^{-3} \mathrm{NaOH}$ flowing at $0.25 \mathrm{~cm}^{3} \cdot \mathrm{min}^{-1}$ was used to wash the column.

Before analysis, the filtrates were filtered by a syringe-driven filter unit (Millex-SV, $5.00 \mu \mathrm{m})$.

\subsubsection{Oligomeric Sugar Content}

To determine the total sugar content, the samples were hydrolyzed to convert the oligomeric sugars into monomeric sugars. Two $5 \mathrm{~cm}^{3}$ samples of each fraction were placed in tubes of $15 \mathrm{~cm}^{3}$. Samples of $100 \mathrm{~mm}^{3}$ and $200 \mathrm{~mm}^{3}$ of $1000 \mathrm{~kg} \cdot \mathrm{m}^{-3}$ sulfuric acid were added to achieve final concentrations of $2 \%$ and $4 \%$, respectively. The tubes were then hydrolyzed for one hour in an autoclave at $121{ }^{\circ} \mathrm{C}$. The oligomeric sugar content was calculated as the total sugar content minus the monomeric sugars measured in Section 2.4.3 (without acid hydrolysis).

\subsubsection{Sodium and Sulfur}

Sodium and sulfur were determined by emission spectroscopy using an emission spectrophotometer plasma commonly called Inductively Coupled Plasma (ICP). The instrument used was a Thermo Fisher Model iCAP6500 Duo.

\subsubsection{Molecular Weight}

To determine the molecular weight of the lignin, gel permeation chromatography was used. The system employed three columns and three detectors in series. Columns can separate molecules having molecular weights between $100 \mathrm{Da}$ and $1000 \mathrm{kDa}$. The detectors used were UV detector and MALLS detector (Multi-angle laser light scattering). The solvent used to solubilize the lignin was tetrahydrofuran (THF).

Since lignin is not soluble in THF, the lignin samples were modified by "acetobromination" to solubilize them. The acetobromination of lignin was carried out as follows:

A sample of $10 \mathrm{mg}$ of lyophilized lignin was weighed in a $40-\mathrm{cm}^{3}$ flask. Then, $2.5 \mathrm{~cm}^{3}$ of acetyl bromide/acetic acid $(8: 92 \mathrm{v} / \mathrm{v})$ were added. The mixture was digested at $50{ }^{\circ} \mathrm{C}$ for $2 \mathrm{~h}$ with occasional stirring. The solvent was evaporated using a rotary evaporator at $40{ }^{\circ} \mathrm{C}$ for $15 \mathrm{~min}$ under a vacuum of $30 \mathrm{~mm} \mathrm{Hg}$. The sample was dried in the lyophilizer overnight. The lignin obtained was dissolved in THF stabilized by BHT (butylated hydroxytoluene). About $1 \mathrm{~cm}^{3}$ of the solution was filtered using a polytetrafluoroethylene (PTFE) filter of $0.2 \mu \mathrm{m}$ porosity.

A solution of BHT-THF having a flow rate of $1 \mathrm{~cm}^{3} \cdot \mathrm{min}^{-1}$ was used as the eluent. The analysis was performed after injecting $75 \mathrm{~mm}^{3}$ of the sample. Signal detection was performed using the two detectors: MALLS and UV.

\subsubsection{Fourier-Transform Infrared Spectroscopy (FTIR) Analysis}

FTIR spectroscopy was employed using a Nicolet-6700 Fourier Transform Infrared Spectrometer with a universal attenuated total reflection (ATR) accessory for lignin samples to understand the changes in functional groups of the lignin structure. Spectra from 800 to $4000 \mathrm{~cm}^{-1}$ were collected for the sample powders in absorbance mode with 64 scans per spectrum at $4 \mathrm{~cm}^{-1}$ resolution. 


\subsubsection{Functional Groups}

Quantitative ${ }^{31} \mathrm{P}$ NMR spectra of all lignin preparations were obtained using published procedures. Approximately $30-40 \mathrm{mg}$ of dry lignin was dissolved in $500 \mathrm{~mm}^{3}$ of anhydrous pyridine and deuterated chloroform $(1.6: 1, v / v)$ under constant stirring. This was followed by the addition of $100 \mathrm{~mm}^{3}$ of cyclohexanol $\left(23.76 \mathrm{~kg} \cdot \mathrm{m}^{-3}\right.$ in pyridine and deuterated chloroform 1.6:1, v/v) used as an internal standard and $50 \mathrm{~mm}^{3}$ of chromium (III) acetylacetonate solution $\left(5.5 \mathrm{~kg} \cdot \mathrm{m}^{-3}\right.$ in anhydrous pyridine and deuterated chloroform $1.6: 1, v / v)$ used as a relaxation agent. Finally, $100 \mathrm{~mm}^{3}$ of phosphitylating reagent (2-chloro4,4,5,5-tetramethyl-1,3,2-dioxaphospholane: TMDP) was added and the vial was sealed and shaken to ensure thorough mixing. The mixture was transferred into a 5-mm NMR tube for subsequent NMR analysis.

All NMR experiments were carried out at $25^{\circ} \mathrm{C}$ on a VARIAN Unity INOVA 500 NMR spectrometer (serial number: 001059) operated at a $1 \mathrm{H}$ frequency of $500.13 \mathrm{MHz}$ and equipped with a $5-\mathrm{mm}$ broadband inverse probe. ${ }^{31} \mathrm{P}$ NMR spectra were recorded with 32,768 data points and a spectral width of $60,606.06 \mathrm{~Hz}$. A relaxation delay of $5 \mathrm{~s}$ was used, and the number of scans was 512 . The ${ }^{31} \mathrm{P}$ chemical shifts were referenced with respect to water signal at $132.2 \mathrm{ppm}$. Spectra were processed and analyzed using MestReNova 8.1 software package. All chemical shifts are reported relative to the products of TMDP with cyclohexanol, which has been observed to give a sharp signal at $145.15 \mathrm{ppm}$ referenced from water signal (132.2 ppm) for the phosphitylating reagent. The content of hydroxyl groups was obtained by integration of the following spectral regions: aliphatic hydroxyls (150.4-145.5 ppm), condensed phenolic units (Diphenylmethane (DPM): 144.4-143.1, 4-O-5':143.1-141.7, and 5-5':141.7-140.8 ppm), condensed phenolic units (143.1-141.7 ppm), guaiacyl phenolic hydroxyls (140.3-138.3 ppm), p-hydroxylphenyl phenolics (138.3-137.3 ppm and $136.8-136.5 \mathrm{ppm})$, and carboxylic acids (135.9-134.0 ppm).

\subsubsection{Calculations}

The solute retention is calculated according to Equation (1).

$$
\text { Retention } \%=\mathrm{mr} / \mathrm{mi} \times 100=(\mathrm{Cr} \times \mathrm{Vr}) /(\mathrm{Ci} \times \mathrm{Vi}) \times 100
$$

where

- $\quad \mathrm{mr}$ and $\mathrm{mi}$ are solute mass in the retentate and the pre-hydrolysate, respectively;

- $\mathrm{Cr}$ and $\mathrm{Ci}$ are solute concentrations in the retentate and the pre-hydrolysate, respectively; and

- $\quad \operatorname{Vr}$ and Vi are retentate and pre-hydrolysate volume, respectively.

\subsubsection{Statistics}

Error bars in this study represent standard deviations. They were calculated using Microsoft Excel from at least two replicate measurements.

\section{Results}

In this study, the membrane efficiency and its effect on lignin and sugar recovery will not be discussed. In fact, this was already investigated in a previously published paper [18]. The membrane which gave the best results in terms of lignin and sugars retention, flux through the membrane, and resistance to fouling was used in this work (1-kDa membrane). The concentration experiments were carried out under the same conditions (temperature $=60{ }^{\circ} \mathrm{C}$ and concentration factor $=5$ ). Lignin and sugar retentions were maintained constant for almost all experiments (99.1\% and $99.7 \%$, respectively).

\subsection{Filtration Rate}

3.1.1. Effect of Sulfuric Acid Concentration and Filtration Temperature

The effects of sulfuric acid concentration and temperature on the filtration rate are shown in Figure 2. In general, there is a significant decrease in filterability as the temperature 
increases. With no sulfuric acid added, the filterability of the solution after coagulation decreased from $5216 \mathrm{dm}^{3} \cdot \mathrm{m}^{-2} \cdot \mathrm{h}^{-1}$ at $40{ }^{\circ} \mathrm{C}$ to $2248 \mathrm{dm}^{3} \cdot \mathrm{m}^{-2} \cdot \mathrm{h}^{-1}$ at $45{ }^{\circ} \mathrm{C}$ and then to $21 \mathrm{dm}^{3} \cdot \mathrm{m}^{-2} \cdot \mathrm{h}^{-1}$ at $50^{\circ} \mathrm{C}$. The same tendency was observed with increasing sulfuric acid concentration in a solution from 0 to $14 \mathrm{~kg} \cdot \mathrm{m}^{-3}$. It appears that acidification has a negative effect on filterability, and the best condition was observed when no sulfuric acid was added. At 8.6 and $14 \mathrm{~kg} \cdot \mathrm{m}^{-3}$ of sulfuric acid, the filterability curves were similar. However, a large increase in filterability was observed when no acidification was applied. It is worth mentioning that, without acidification, the recoverable lignin was only the insoluble lignin in the concentrate. This lignin is characterized by its high molecular weight compared to the lignin that is still soluble in the pre-hydrolysate. This can explain the high filterability obtained when acidification was not applied. The soluble lignin is mainly stabilized because of the repulsive forces due to the presence of ionized phenolic hydroxyl and carboxylic groups. To recover higher lignin quantities, an acidification step should be used in the process. This leads to protonation of the dissociated phenolic hydroxyl groups of the lignin. As a result, repulsive forces decrease and more lignin precipitates [27]. With acidification, lignin with a lower molecular weight starts to precipitate [28], thus leading to a decrease in filterability of the solution. At 45 and $50{ }^{\circ} \mathrm{C}$ and after acid addition, the filterability was low, as indicated in Figure 2. At a temperature of $40^{\circ} \mathrm{C}$ and any acid concentration, the filtration rate is significantly higher compared to those obtained at temperatures of 45 and $50{ }^{\circ} \mathrm{C}$.

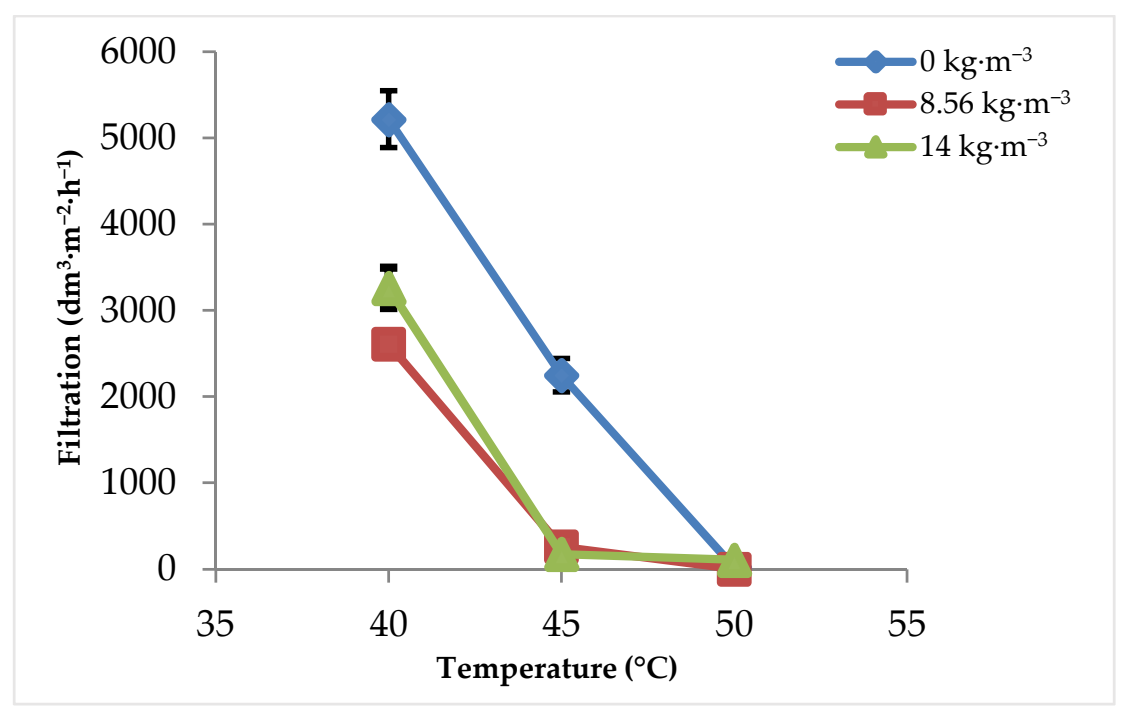

Figure 2. Effect of sulfuric acid concentration and temperature on the filtration flux.

\subsubsection{Effect of Coagulation Time}

The effect of coagulation time on the filtration rate of the lignin-containing solution is shown in Figure 3. After 60 and $120 \mathrm{~min}$ of coagulation, the filtration rates were poor, 25.1 and $33.4 \mathrm{dm}^{3} \cdot \mathrm{m}^{-2} \cdot \mathrm{h}^{-1}$, respectively. The filterability was increased to $2608 \mathrm{dm}^{3} \cdot \mathrm{m}^{-2} \cdot \mathrm{h}^{-1}$ when the coagulation time was increased to $180 \mathrm{~min}$. This is logical because giving enough time for the lignin molecules to sufficiently coagulate can be beneficial for the filtration step. As discussed before, when the concentrate is acidified, more molecules of lignin with a low molecular weight are precipitated. These low molecular weight molecules require time to agglomerate and form larger particles. The particles of lignin should have a reasonable size in order to obtain a high filtration rate, and this can be achieved by allowing sufficient time for the coagulation step. As a result, a considerable increase in the flux is achieved. Furthermore, this will reduce the size of the filter and will allow savings in the capital cost of the filtration unit. 


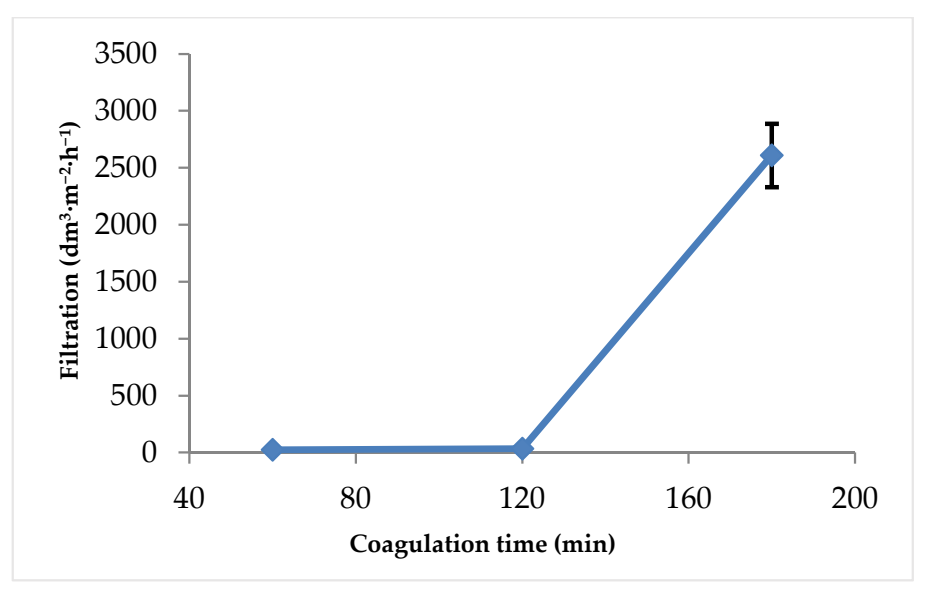

Figure 3. Effect of coagulation time on filtration step with the following conditions: sulfuric acid concentration at $8.56 \mathrm{~kg} \cdot \mathrm{m}^{-3}$ and filtration temperature at $40{ }^{\circ} \mathrm{C}$.

\subsection{Purity of Lignin}

\subsubsection{Effect of Coagulation Time}

The purity of lignin is an important parameter. Elements such as sulfur, calcium, and sodium can be found in the final lignin product. The variation in the levels of several elements present in the lignin cake as a function of coagulation time is shown in Figure 4. The sodium content in the pre-hydrolysate is low since chips were not treated with white liquor as in the kraft pulping process. As seen, it is clear that the purity of the obtained lignin is influenced by the coagulation time. In fact, the percentages of calcium and sulfur decrease significantly with increasing coagulation time. Calcium, sulfur, and sugars levels of $4.5 \%, 3.7 \%$, and $4.0 \%$, respectively were measured when the coagulation time was $60 \mathrm{~min}$. The increase in coagulation time to $180 \mathrm{~min}$ led to a decrease in the percentage of calcium $(1.5 \%)$ and sulfur $(1.25 \%)$. However, the sugar level at that point increased to $5.5 \%$. As discussed above, a higher coagulation time leads to higher filtration rates, which allow soluble species to pass easily through the lignin cake and to not be partially retained. Most of the $\mathrm{Na}, \mathrm{S}$, and $\mathrm{Ca}$ are soluble in the acidified filtrate and are expected to pass through the filter after good coagulation. For this reason, their levels decreased as the coagulation time increased. Most of the sugars are in the oligomeric form and are bound to lignin. As the coagulation time increases, the lignin particles (together with the sugars) become larger and more sugars are precipitated with the lignin. This leads to an increase in the lignin cake's sugar content.

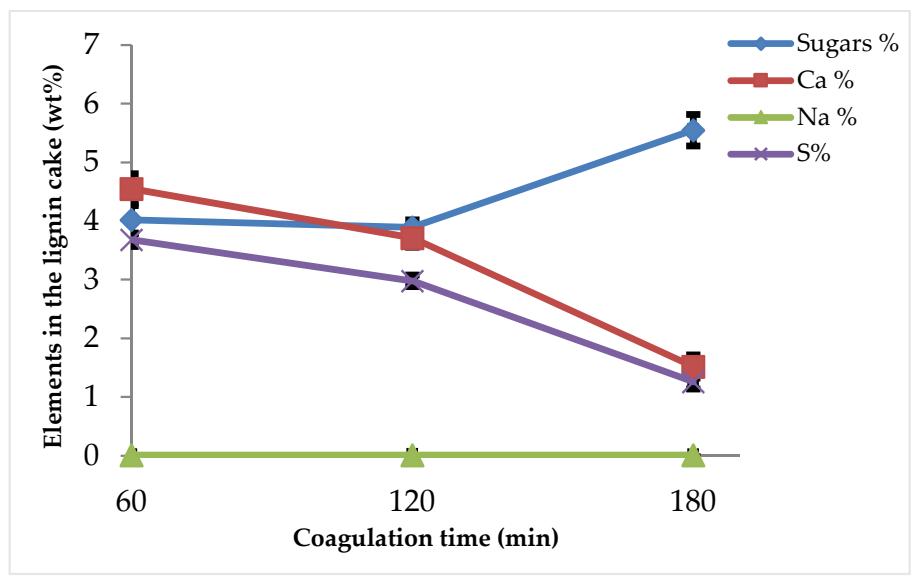

Figure 4. Effect of the coagulation time on sugar, calcium, sodium, and sulfur percentages in the lignin cake at a temperature of $40{ }^{\circ} \mathrm{C}$ and $8.56 \mathrm{~kg} \cdot \mathrm{m}^{-3}$. 


\subsubsection{Effect of Sulfuric Acid Concentration and Filtration Temperature}

Figure 5 presents the percentages of $\mathrm{Na}, \mathrm{S}, \mathrm{Ca}$, and sugars in the lignin cake as a function of sulfuric acid in the solution at temperatures of 40,45 , and $50{ }^{\circ} \mathrm{C}$. At $14.7 \mathrm{~kg} \cdot \mathrm{m}^{-3}$ of acid, the $\mathrm{Ca}, \mathrm{Na}$, and $\mathrm{S}$ contents are the lowest at 45 and $50^{\circ} \mathrm{C}$. However, these temperatures are not recommended as the filtration rates are low, as shown in Figure 2. The sugar, $\mathrm{Na}, \mathrm{Ca}$, and $\mathrm{S}$ contents seem to be almost constant at $40{ }^{\circ} \mathrm{C}$, irrespective of the concentration of the sulfuric acid. Thus, the lowest total impurity level of $8.5 \%$ can be achieved at $40{ }^{\circ} \mathrm{C}$ and a sulfuric acid concentration of $5.76 \mathrm{~kg} \cdot \mathrm{m}^{-3}(4.47 \%$ sugars, $0.007 \%$ sodium, $1.79 \%$ sulfur, and $2.23 \%$ calcium).
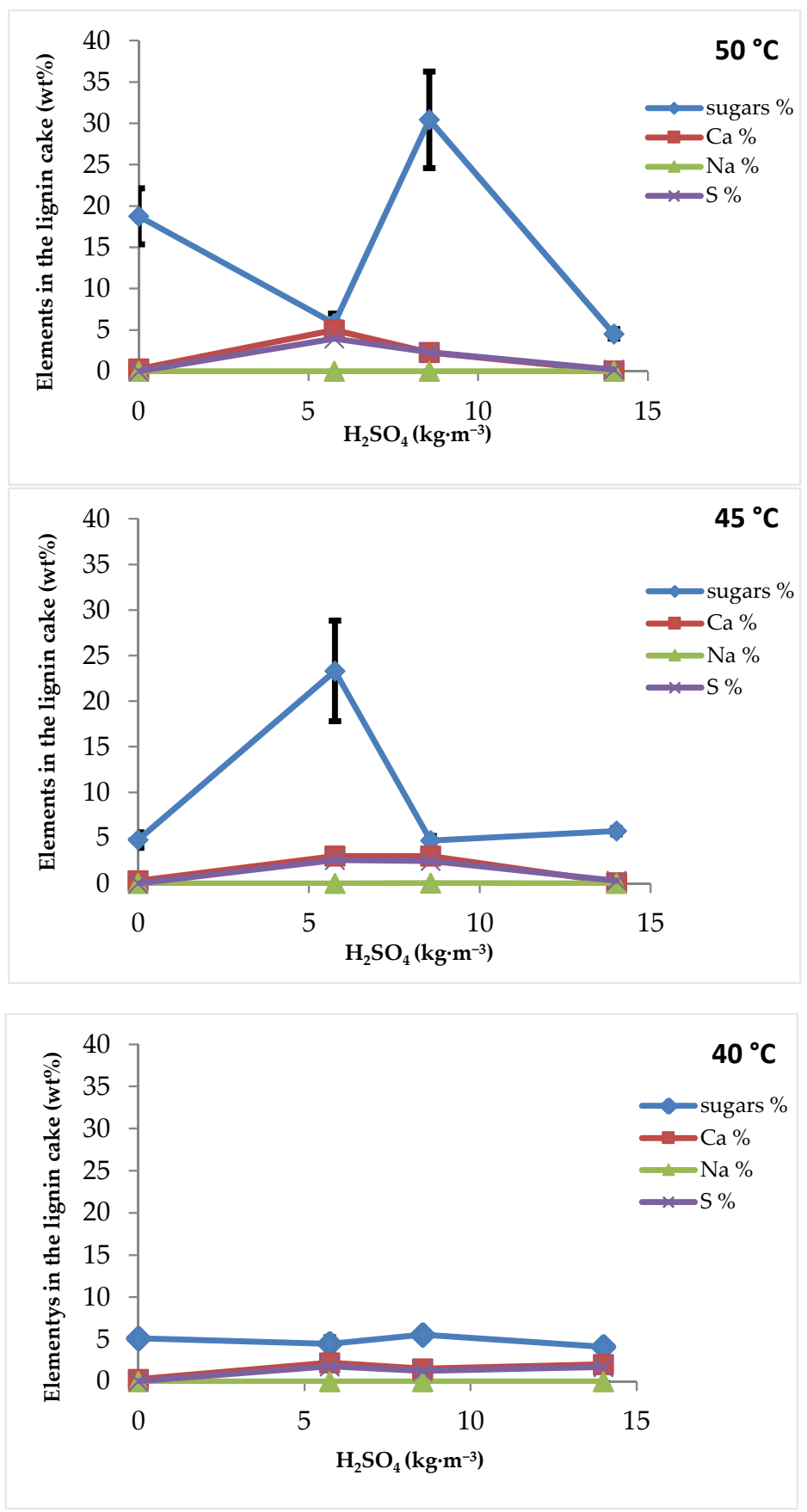

Figure 5. Sugar, calcium, sodium, and sulfur contents in the lignin cake as a function of the sulfuric acid concentration and temperature after $180 \mathrm{~min}$ of coagulation. 


\subsection{Lignin Quantity}

\subsubsection{Effect of Coagulation Time}

The variation in the percentage of lignin recovery as a function of coagulation time is shown in Figure 6 for experiments conducted at $40{ }^{\circ} \mathrm{C}$. In fact, a recovery of about $35 \%$ of the initial lignin was observed using a coagulation time of $60 \mathrm{~min}$. By increasing the coagulation time to 120 or $180 \mathrm{~min}$, lignin recovery increased to 40.3 and $51 \%$, respectively. As the coagulation time is increased, molecules of lignin (which are in suspension) have sufficient time to coagulate and form agglomerates of lignin that are large enough to be retained on the filter cake. At any time, fine lignin particles that did not agglomerate will pass through the cake and the filter. These fine particles are present in a considerable amount when coagulation time is short. A coagulation time of $180 \mathrm{~min}$ gave the lowest content of impurities in the lignin cake, as shown in Figure 6. The impurity level was $8.3 \%$.

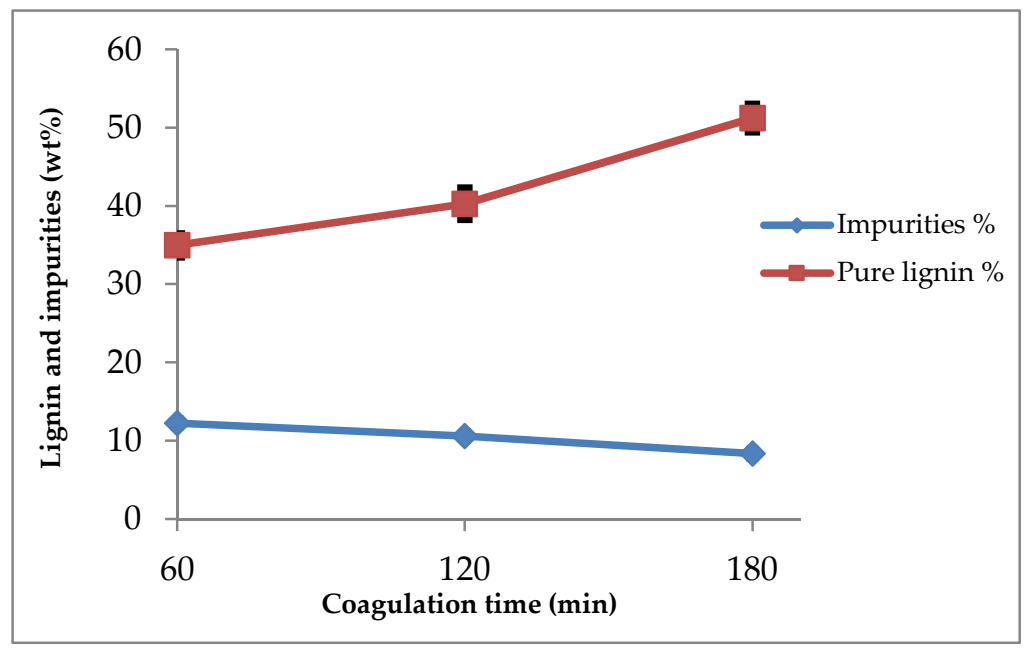

Figure 6. Effect of coagulation time on the amount of recovered lignin and its purity at a temperature of $40{ }^{\circ} \mathrm{C}$ and a sulfuric acid concentration of $8.56 \mathrm{~kg} \cdot \mathrm{m}^{-3}$.

\subsubsection{Effect of Sulfuric Acid Concentration and Filtration Temperature}

Figure 7 presents the percentages of lignin recovered and the amounts of impurities as a function of sulfuric acid concentration and filtration temperatures of 40,45 , and $50^{\circ} \mathrm{C}$. The highest amount of lignin recovered in this study was $55.4 \%$. It was recovered at $50{ }^{\circ} \mathrm{C}$ and a sulfuric acid concentration of $8.5 \mathrm{~kg} \cdot \mathrm{m}^{-3}$. However, under the same conditions, the cake also contained more than $35 \%$ of impurities. At the same temperature of $50{ }^{\circ} \mathrm{C}$ and at other sulfuric acid concentrations $\left(0,5.7\right.$, and $\left.14 \mathrm{~kg} \cdot \mathrm{m}^{-3}\right)$, not more than $43 \%$ of the initial lignin was recovered. The same observations can be made for the experiments conducted at $45^{\circ} \mathrm{C}$ (Figure 7). Even though more than $40 \%$ of the initial lignin was recovered, the lignin cake still contained a high percentage of impurities when 5.7 and $8.5 \mathrm{~kg} \cdot \mathrm{m}^{-3}$ of sulfuric acid were used. Notably, a low percentage of lignin was recovered when no sulfuric acid was used. Except for the $0 \mathrm{~kg} \cdot \mathrm{m}^{-3}$ sulfuric acid concentration, all the other experiments carried out at $40{ }^{\circ} \mathrm{C}$ showed a recovery of lignin higher than $45 \%$ and a level of impurity less than $8.5 \%$.

\subsection{Molecular Weight and Molecular Weight Distribution}

Table 2 shows the molecular weight and molecular weight distribution of different fractions of lignin obtained by varying the sulfuric acid concentration, the coagulation time, and the filtration temperature. According to the results, it appears that these parameters influence the molecular weight distribution of lignin. 

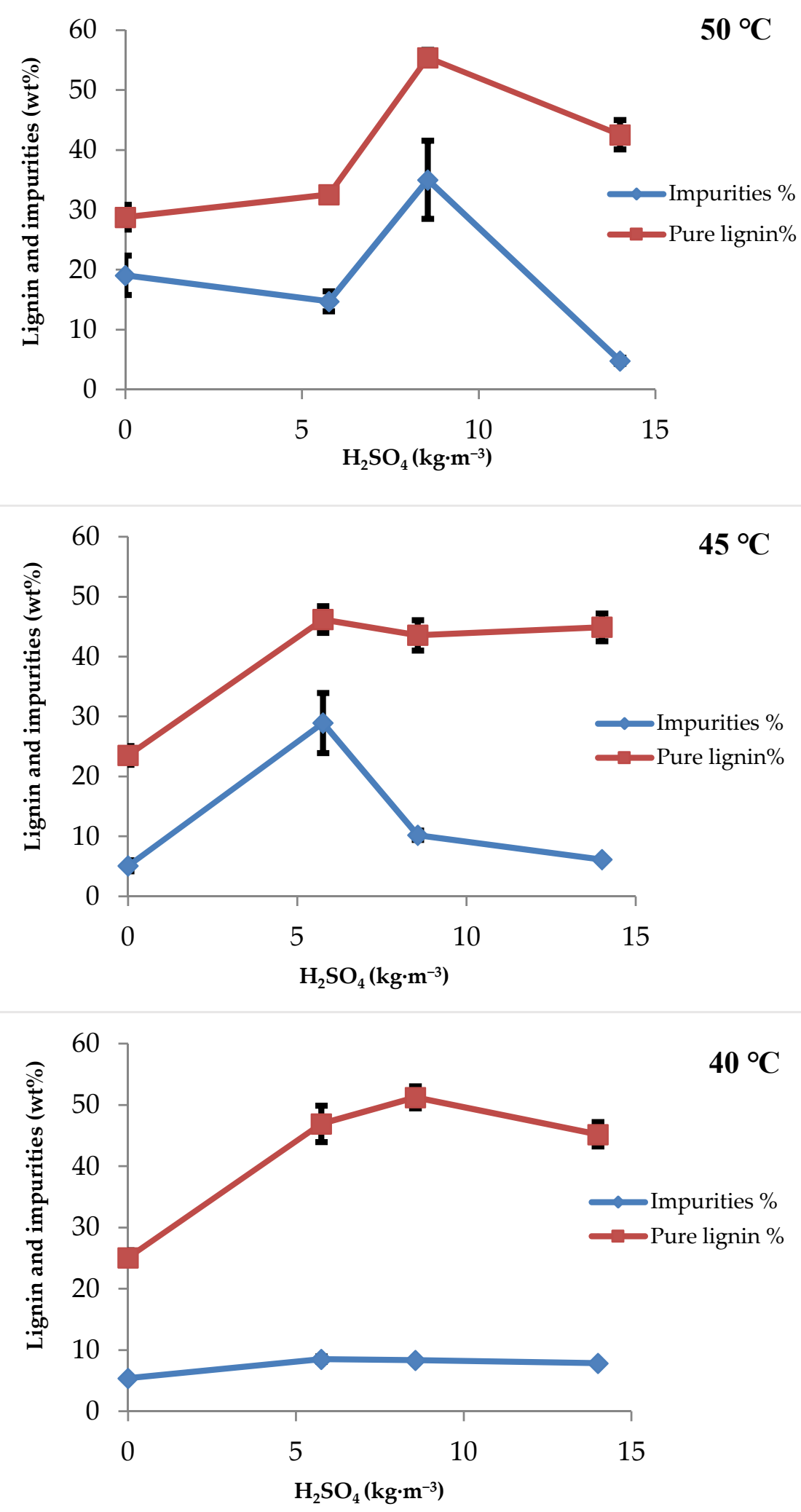

Figure 7. Percentages of lignin recovered and impurities at different filtration temperatures and 180 min of coagulation. 
Table 2. Molecular weight and molecular weight distribution of the recovered lignin.

\begin{tabular}{cccc}
\hline Lignin Precipitation Parameters & & MALLS & \\
\cline { 2 - 4 } & $\mathbf{M}_{\mathbf{W}}$ & $\mathbf{M n}$ & $\mathbf{M}_{\mathbf{W}} / \mathbf{M n}$ \\
\hline $\mathrm{A} 1\left(40^{\circ} \mathrm{C} ; 14 \mathrm{~kg} \cdot \mathrm{m}^{-3}, 180 \mathrm{~min}\right)$ & 2160 & 1860 & 1.16 \\
$\mathrm{~A} 2\left(40^{\circ} \mathrm{C} ; 8.5 \mathrm{~kg} \cdot \mathrm{m}^{-3}, 180 \mathrm{~min}\right)$ & 1270 & 1040 & 1.22 \\
$\mathrm{~A} 3\left(40^{\circ} \mathrm{C} ; 5.7 \mathrm{~kg} \cdot \mathrm{m}^{-3}, 180 \mathrm{~min}\right)$ & 1540 & 1310 & 1.18 \\
$\mathrm{~A} 4\left(40^{\circ} \mathrm{C} ; 0 \mathrm{~kg} \cdot \mathrm{m}^{-3}, 180 \mathrm{~min}\right)$ & 4285 & 3725 & 1.15 \\
$\mathrm{~B} 1\left(45^{\circ} \mathrm{C} ; 14 \mathrm{~kg} \cdot \mathrm{m}^{-3}, 180 \mathrm{~min}\right)$ & 3280 & 2555 & 1.28 \\
$\mathrm{~B} 2\left(45^{\circ} \mathrm{C} ; 8.5 \mathrm{~kg} \cdot \mathrm{m}^{-3}, 180 \mathrm{~min}\right)$ & 2865 & 2115 & 1.35 \\
$\mathrm{~B} 3\left(45^{\circ} \mathrm{C} ; 5.7 \mathrm{~kg} \cdot \mathrm{m}^{-3}, 180 \mathrm{~min}\right)$ & 2610 & 1445 & 1.81 \\
$\mathrm{~B} 4\left(45^{\circ} \mathrm{C} ; 0 \mathrm{~kg} \cdot \mathrm{m}^{-3}, 180 \mathrm{~min}\right)$ & 4160 & 3740 & 1.11 \\
$\mathrm{C} 1\left(50^{\circ} \mathrm{C} ; 14 \mathrm{~kg} \cdot \mathrm{m}^{-3}, 180 \mathrm{~min}\right)$ & 4015 & 3090 & 1.30 \\
$\mathrm{C} 2\left(50^{\circ} \mathrm{C} ; 8.5 \mathrm{~kg} \cdot \mathrm{m}^{-3}, 180 \mathrm{~min}\right)$ & 3550 & 2350 & 1.51 \\
$\mathrm{C} 3\left(50^{\circ} \mathrm{C} ; 5.7 \mathrm{~kg} \cdot \mathrm{m}^{-3}, 180 \mathrm{~min}\right)$ & 2890 & 1980 & 1.46 \\
$\mathrm{C} 4\left(50^{\circ} \mathrm{C} ; 0 \mathrm{~kg} \cdot \mathrm{m}^{-3}, 180 \mathrm{~min}\right)$ & 2610 & 2140 & 1.22 \\
$\mathrm{D} 2\left(40^{\circ} \mathrm{C} ; 8.5 \mathrm{~kg} \cdot \mathrm{m}^{-3}, 120 \mathrm{~min}\right)$ & 1890 & 1095 & 1.73 \\
$\mathrm{D} 3\left(40^{\circ} \mathrm{C} ; 8.5 \mathrm{~kg} \cdot \mathrm{m}^{-3}, 60 \mathrm{~min}\right)$ & 2320 & 1530 & 1.52 \\
\hline
\end{tabular}

\subsubsection{Effect of Filtration Temperature}

The first trend that can be observed from the data in Table 2 is that the molecular weight changes as a function of the filtration temperature, as shown for examples in lignin samples A1, B1, and C1. These samples were obtained using the same sulfuric acid concentration $\left(14 \mathrm{~kg} \cdot \mathrm{m}^{-3}\right)$, the same coagulation time $(180 \mathrm{~min})$, and different temperatures $\left(40,45\right.$, and $50^{\circ} \mathrm{C}$ for $\mathrm{A} 1, \mathrm{~B} 1$, and $\mathrm{C} 1$, respectively). Using MALLS, molecular weights of 2160,3280 , and $4015 \mathrm{Da}$ were obtained at 40,45 , and $50^{\circ} \mathrm{C}$, respectively. The same trend can be observed at other different acid concentrations and coagulation times. In general, at a given acid concentration and coagulation time, the results in Table 2 clearly show that the molecular weight increases as the filtration temperature is increased.

\subsubsection{Effect of Coagulation Time}

The coagulation time also has a significant effect on the molecular weight of lignin. Samples D3, D2, and A2 were obtained using the same filtration temperature of $40{ }^{\circ} \mathrm{C}$ and the same sulfuric acid concentration of $8.5 \mathrm{~kg} \cdot \mathrm{m}^{-3}$ but using different coagulation times of 60,120 , and $180 \mathrm{~min}$, respectively. In these samples, a clear decrease in MALLS molecular weight (from 2320 to 1890 and then to $1270 \mathrm{Da}$, respectively) is observed with increasing coagulation time. As the coagulation time was extended, small molecules of lignin were given the chance to precipitate and coagulate, which led to a higher contribution of small molecules of lignin in the total molecular weight distribution and, consequently, lower final molecular weight.

\subsubsection{Effect of Acid Concentration}

It is known that the molecular weight of the precipitated lignin decreases as a function of acid strength in the solution [28]. This means that, with higher acidity, more molecules of lignin with low molecular weight are precipitated. This trend can be clearly observed in series A and B in Table 2. When no sulfuric acid is added to the solution, the sample of lignin obtained (A4) had a high molecular weight (4285 Da). Increasing the acid concentration in the solution to $5.7 \mathrm{~kg} \cdot \mathrm{m}^{-3}$ resulted in a lower molecular weight of $1540 \mathrm{Da}$ (A3). At $8.5 \mathrm{~kg} \cdot \mathrm{m}^{-3}$, the molecular weight decreased to $1270 \mathrm{Da}(\mathrm{A} 2)$. The same trend is observed in B experiments. The molecular weight of lignin dropped from $4160 \mathrm{Da}$ (B4) (without acidification) to $2610 \mathrm{Da}$ using $5.7 \mathrm{~kg} \cdot \mathrm{m}^{-3}$ of sulfuric acid (B3). This is expected since, as the acid concentration increases, more molecules having low molecular weights are precipitated and contribute to the decrease in overall molecular weight of the lignin. However, with severe acidification, the molecular weight of the lignin starts to increase. This is observed when, for example, the concentrate in series A (A1) was acidified using 
$14.7 \mathrm{~kg} \cdot \mathrm{m}^{-3}$ of acid. The molecular weight increased from $1270 \mathrm{Da}\left(\right.$ at $8.5 \mathrm{~kg} \cdot \mathrm{m}^{-3}$ of sulfuric acid (A2)) to $2160 \mathrm{Da}$ (at $14.7 \mathrm{~kg} \cdot \mathrm{m}^{-3}$ of sulfuric acid (A1)). For the B series obtained at $45^{\circ} \mathrm{C}$, the molecular weight decreased when the acid concentration increased from 0 to $5.7 \mathrm{~kg} \cdot \mathrm{m}^{-3}$ but started to increase as higher acid concentrations were used $\left(8.5\right.$ and $\left.14 \mathrm{~kg} \cdot \mathrm{m}^{-3}\right)$. It seems that, as the temperature increases, high acid concentration does not lead to lower molecular weight of the lignin (experiments A1, B1, and C1).

\subsection{Particles Size}

\subsubsection{Effect of Acid Concentration}

It can be clearly observed from Figure 8 that lignin particle size changes as a function of acid concentration. Without acidification, most particles of lignin obtained have very large sizes (A4).

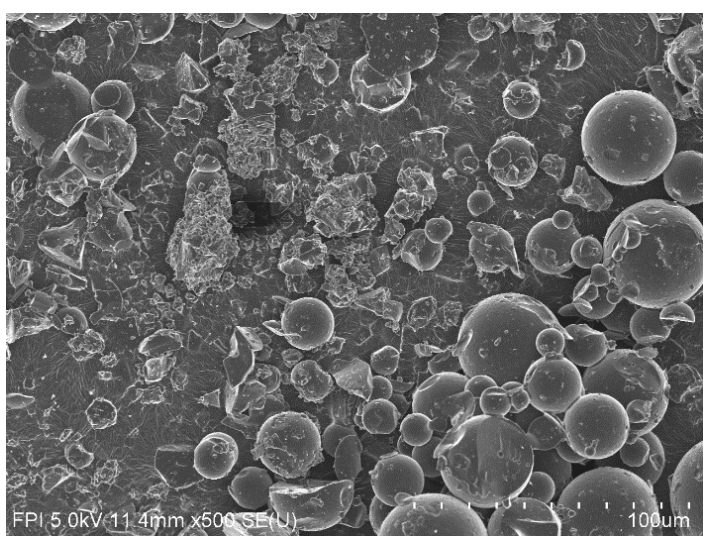

(a)

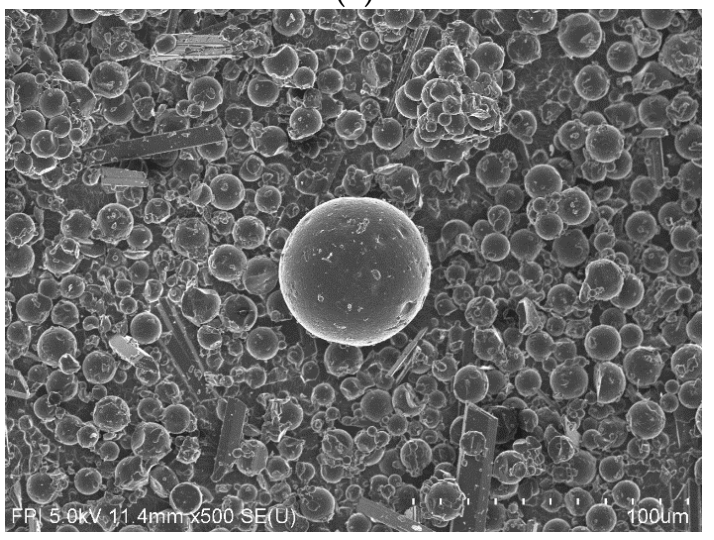

(c)

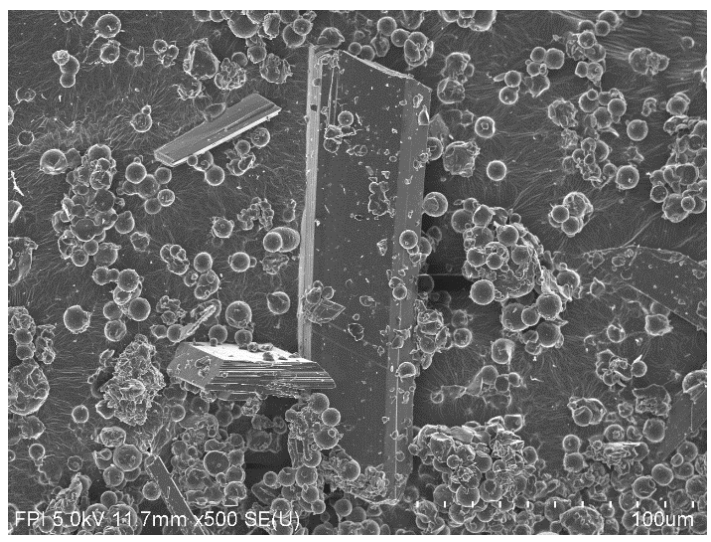

(b)

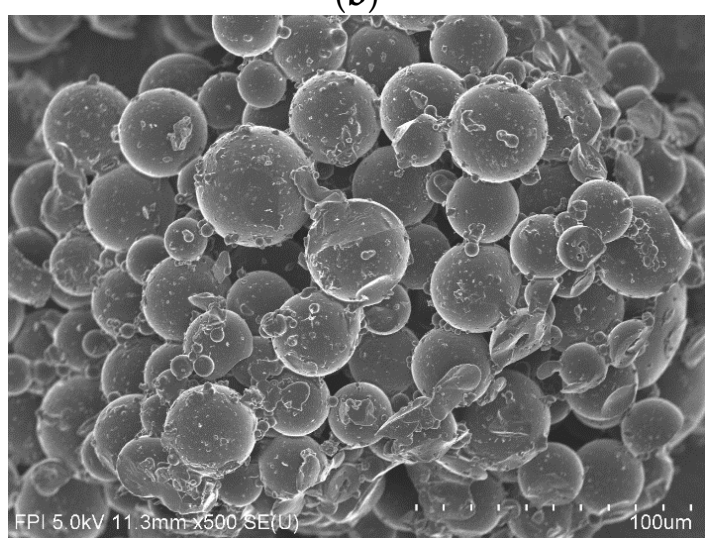

(d)

Figure 8. Scanning electron microscopy (SEM) micrographs of lignin obtained (the scale bar is $100 \mu \mathrm{m}):(\mathrm{a})=\mathrm{A} 1\left(40{ }^{\circ} \mathrm{C}\right.$; $\left.14 \mathrm{~kg} \cdot \mathrm{m}^{-3} \mathrm{H}_{2} \mathrm{SO}_{4}, 180 \mathrm{~min}\right),(\mathrm{b})=\mathrm{A} 2\left(40{ }^{\circ} \mathrm{C} ; 8.5 \mathrm{~kg} \cdot \mathrm{m}^{-3} \mathrm{H}_{2} \mathrm{SO}_{4}, 180 \mathrm{~min}\right),(\mathrm{c})=\mathrm{A} 3\left(40{ }^{\circ} \mathrm{C} ; 5.7 \mathrm{~kg} \cdot \mathrm{m}^{-3} \mathrm{H}_{2} \mathrm{SO}_{4}, 180 \mathrm{~min}\right)$, and $(\mathrm{d})=\mathrm{A} 4\left(40{ }^{\circ} \mathrm{C} ; 0 \mathrm{~kg} \cdot \mathrm{m}^{-3} \mathrm{H}_{2} \mathrm{SO}_{4}, 180 \mathrm{~min}\right)$.

When acid was used, more lignin with small particles became visible (A3). The contribution of lignin particles with smaller size in the final fractions of lignin became higher with higher acid concentrations (A2). This is perfectly consistent with the discussion above about molecular weight results. It was seen that the molecular weight of lignin decreased as a function of acidification. Paradoxically, the only sample that deviated from this tendency was lignin A1 $\left(40{ }^{\circ} \mathrm{C} ; 14 \mathrm{~kg} \cdot \mathrm{m}^{-3}, 180 \mathrm{~min}\right)$, which is the most acidified lignin. This showed an increase in its molecular weight after excessive acidification $\left(14 \mathrm{~kg} \cdot \mathrm{m}^{-3}\right)$. What is surprising is that this lignin also deviated from the particles size observations. In fact, the size of lignin particles increased when the acidification passed from 8.5 to $14 \mathrm{~kg} \cdot \mathrm{m}^{-3}$ (A2 to A1). This confirms that it was not an error of analysis or operation 
but suggests that there is a reason behind this surprising result. These results are also confirmed when the filtration behavior is taken into consideration. In fact, it is clearly shown in Figure 2 that the filtration flux decreased significantly when acidification was applied. When the solution of pre-hydrolysate was over-acidified $\left(14 \mathrm{~kg} \cdot \mathrm{m}^{-3}\right)$, however, the filtration flux started to increase again. This confirmed that the molecular weight and particles size of lignin increased when $14 \mathrm{~kg} \cdot \mathrm{m}^{-3}$ of sulfuric acid was used at $40{ }^{\circ} \mathrm{C}$.

\subsubsection{Effect of Coagulation Time}

Coagulation time is an important parameter that should be taken into consideration during a precipitation and filtration process. Figure 9 shows that particles size increased as a function of coagulation time. This is in perfect coherence with the results obtained above (Section 3.1.2). In fact, when a long coagulation time is used, molecules of lignin had enough time to agglomerate and make particles with large sizes. This explains the higher filtration flux obtained when $180 \mathrm{~min}$ of coagulation time was applied. However, using a short coagulation time led to the formation of small particles due to insufficient time for lignin particles to agglomerate with each other and to form particles big enough to facilitate the filtration. These results are also consistent with those obtained for molecular weight (Section 3.4.2). The molecular weight of lignin decreased when a higher coagulation time was used. This is logical since the contribution of molecules with low molecular weight became higher, which led to a lower average molecular weight and, at the same time, contributed to an increase in the size of lignin particles.

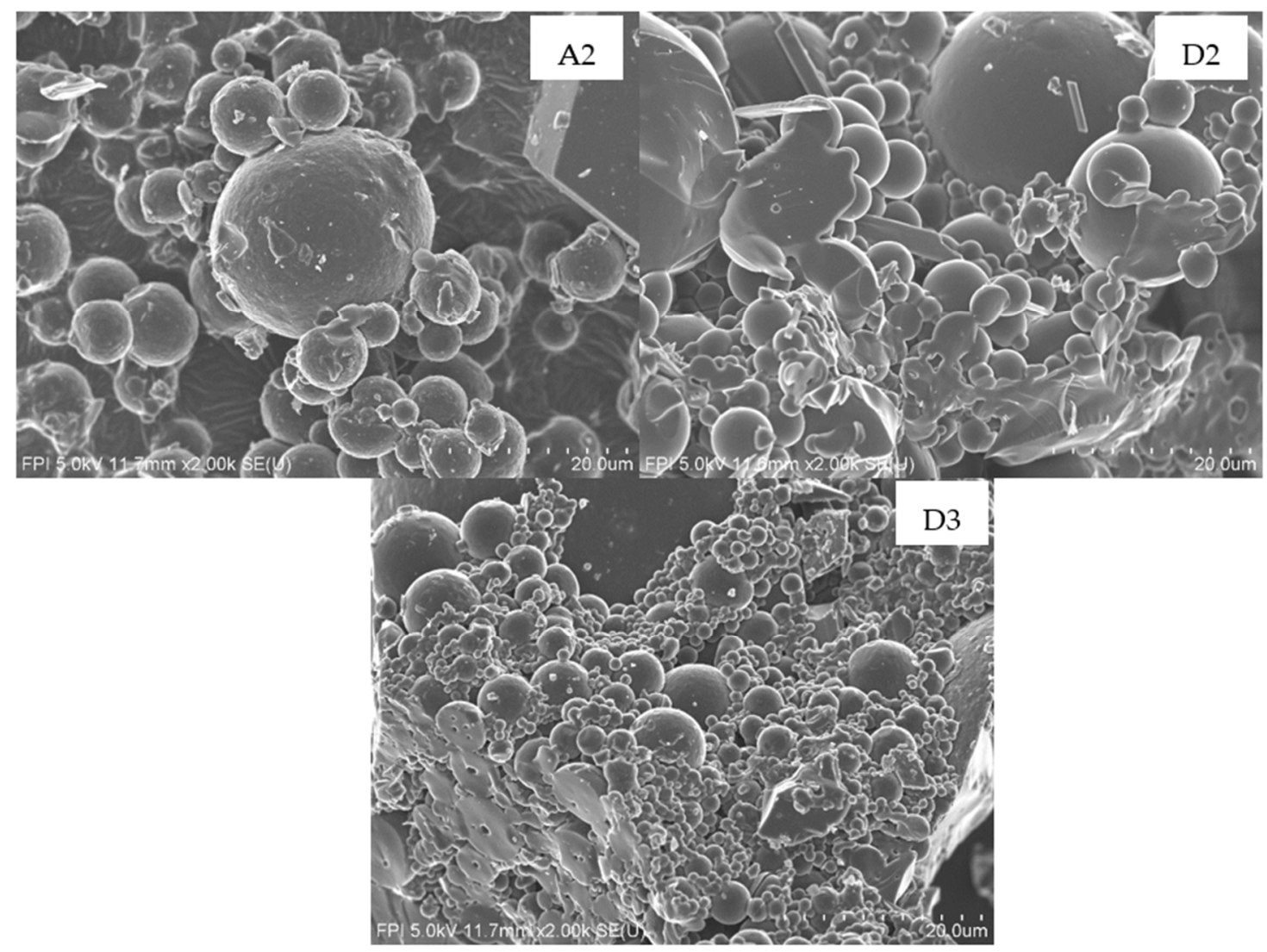

Figure 9. SEM micrographs of lignin obtained (the scale bar is $20 \mu \mathrm{m})$ : (A2) $\left(40{ }^{\circ} \mathrm{C} ; 8.5 \mathrm{~kg} \cdot \mathrm{m}^{-3} \mathrm{H}_{2} \mathrm{SO}_{4}, 180 \mathrm{~min}\right)$, (D2) $\left(40{ }^{\circ} \mathrm{C} ; 8.5 \mathrm{~kg} \cdot \mathrm{m}^{-3} \mathrm{H}_{2} \mathrm{SO}_{4}, 120 \mathrm{~min}\right)$, and (D3) $\left(40{ }^{\circ} \mathrm{C} ; 8.5 \mathrm{~kg} \cdot \mathrm{m}^{-3} \mathrm{H}_{2} \mathrm{SO}_{4}, 60 \mathrm{~min}\right)$.

Based on the results and discussion above, it appears that the optimal conditions to recover lignin from the pre-hydrolysate are $8.5 \mathrm{~kg} \cdot \mathrm{m}^{-3}, 180 \mathrm{~min}$, and $40^{\circ} \mathrm{C}$ for sulfuric acid concentration, coagulation time, and filtration temperature, respectively. These conditions 
were the most advantageous to use because they provided the highest lignin recovery with the highest purity even though no washing step was used. The incorporation of a washing step in the proposed process might enhance the quality and the purity of the lignin. The lignin obtained is also characterized by a low molecular weight and polydispersity.

For the purpose of comparison, lignins extracted from kraft hardwood (KHW) and softwood (KSW) black liquors using a commercial process (LignoForce system ${ }^{\mathrm{TM}}$ ) were analyzed with respect to the molecular weight, FTIR, and ${ }^{13} \mathrm{P}$ NMR analysis and compared with the pre-hydrolysate lignin (PHL) that was obtained using the conditions mentioned above.

The molecular weight distribution of KSW, KHW, and PHL lignins are shown in Figure 10. It can be seen from this figure that PHL lignin has a significantly lower molecular weight and polydispersity index than KSW and KHW lignins. This was confirmed when both UV (A) and MALLS (B) detectors were used. This can be attributed to a higher fraction of small lignin molecules in PHL lignin compared to KSW and KHW lignins. This is clearly highlighted in the elution volumes shown in Figure 10A: 21, 19, and $18 \mathrm{~mL}$ for PHL, KHW, and KSW, respectively. The same trend was observed when the MALLS detector was used. This demonstrates the advantage of pre-hydrolysis treatment (which can be considered a simultaneous depolymerization step) that led to the formation of a lignin with a lower molecular weight and narrower distribution than kraft lignins.
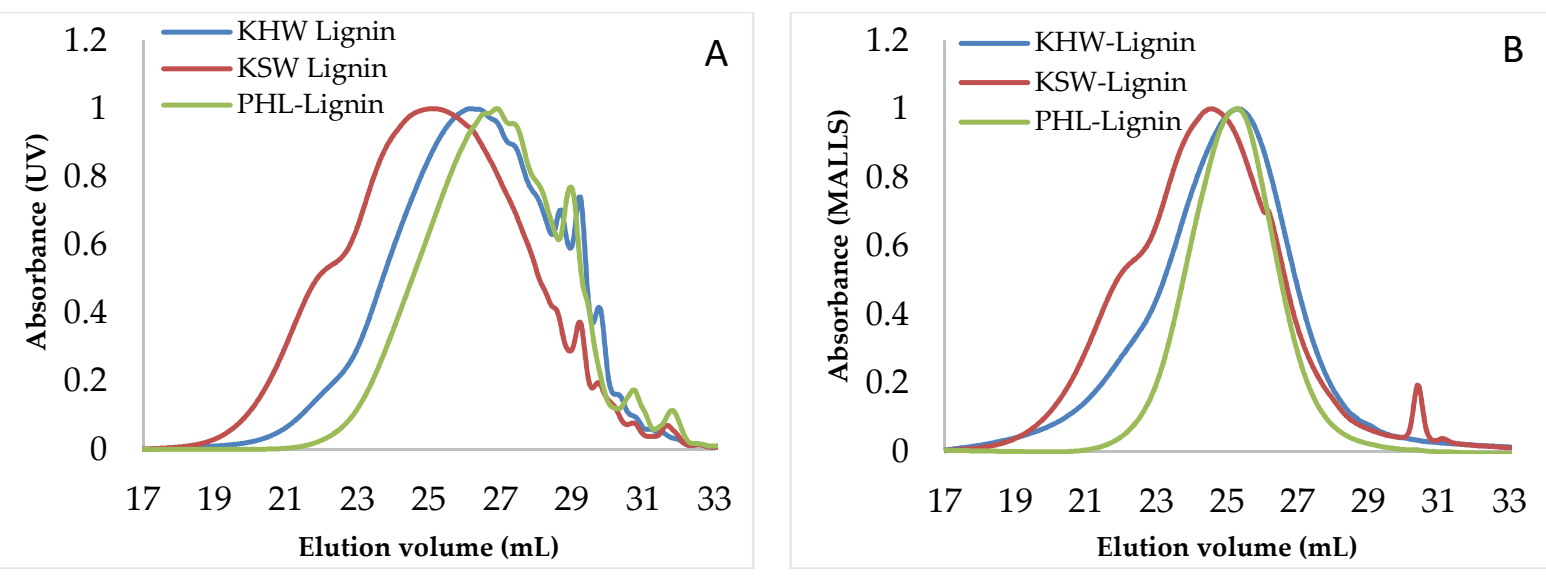

Figure 10. Molecular weight distribution of kraft softwood (KSW), kraft hardwood (KHW), and pre-hydrolysate (PHL) lignins as determined by (A) UV and (B) MALLS.

As shown in Figure 11, FTIR spectrums demonstrated that KSW, KHW, and PHL lignins are rich in hydroxyl groups. The big band around $3400 \mathrm{~cm}^{-1}$ is due to the stretching vibration of phenolic and/or aliphatic hydroxyl groups [29]. The intensity of this band was clearly higher in the case of PHL lignin, indicating the presence of higher hydroxyl group contents compared to KSW and KHW lignins. The absorption peak around $1700 \mathrm{~cm}^{-1}$ is associated to $\mathrm{C}=\mathrm{O}$ stretching from the aldehyde, ketone, and ester groups [30].

The absorption peak at around $1114 \mathrm{~cm}^{-1}$ which is associated to the syringyl units [31] was also higher for PHL and KHW than KSW lignin. This result was expected since it is well known that lignin from hardwood species contains more syringyl groups than lignin from softwood species.

Analyses of the different functional groups of KSW, KHW, and PHL lignins are shown in Figure 12. The ${ }^{31} \mathrm{P}$ NMR spectra show that the number of carboxylic hydroxyl units is almost the same for all fractions of lignin recovered from softwood and hardwood black liquors and from the pre-hydrolysate. However, it appears that the pre-hydrolysate lignin is more reactive than KSW and KHW lignins since there are more phenolic, aliphatic, and total hydroxyl groups in lignin obtained from the pre-hydrolysate than in lignins extracted from softwood and hardwood black liquors. Thus, the pre-hydrolysate lignin could be an excellent candidate for applications within phenol-formaldehyde resins and polyurethane-based materials. 


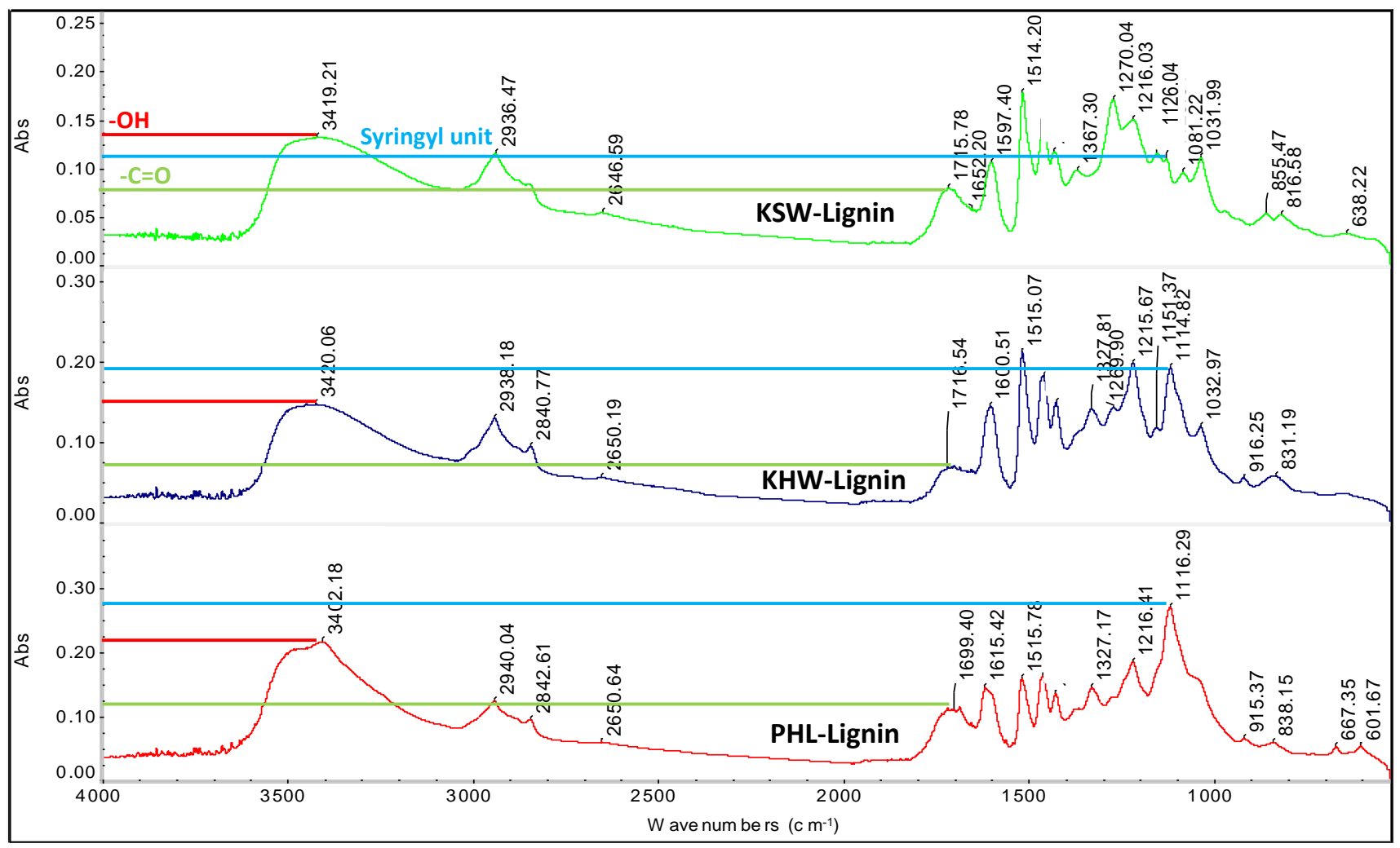

Figure 11. The FTIR of KSW, KHW, and PHL lignin.

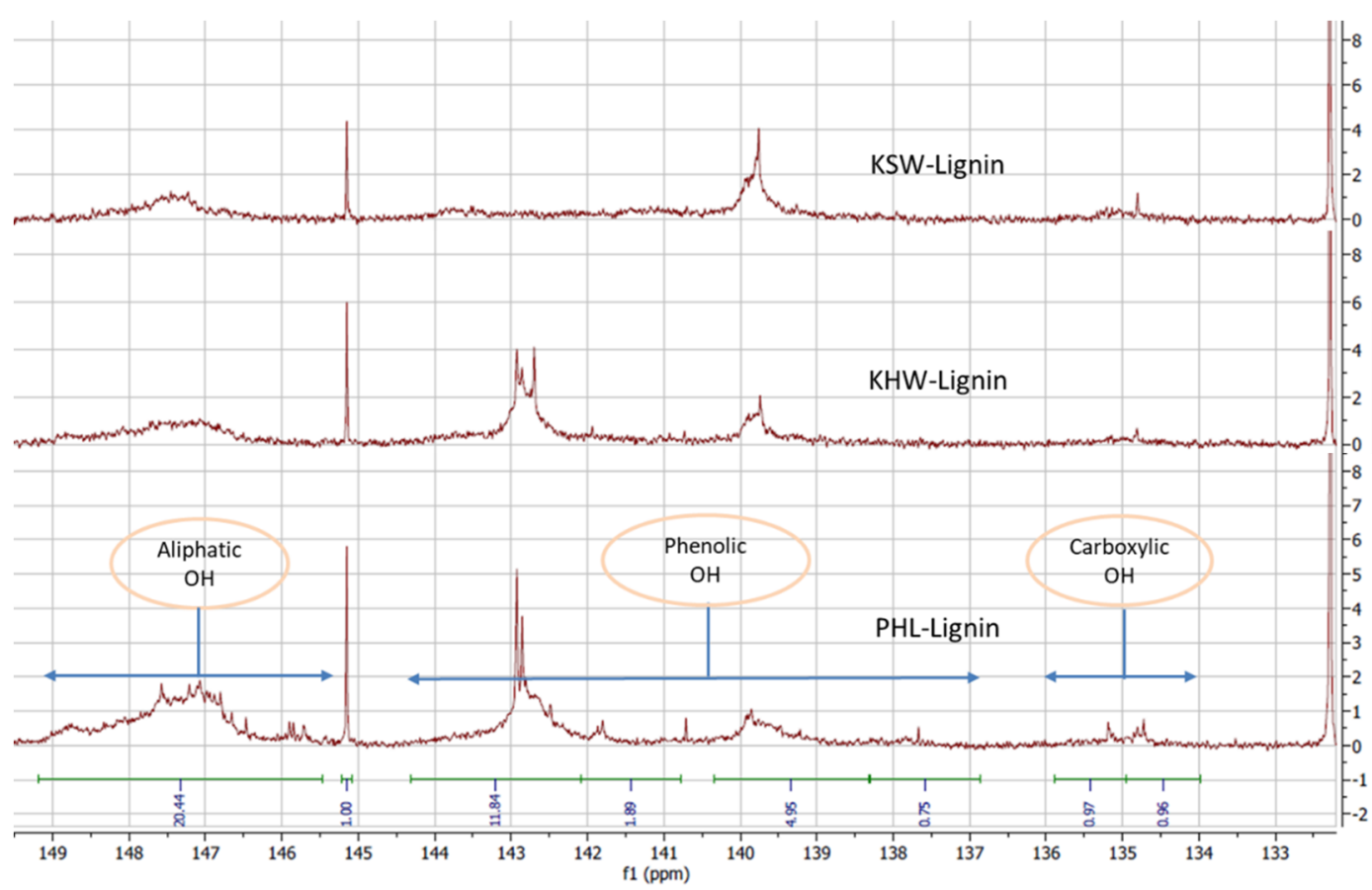

Figure 12. Quantitative ${ }^{31} \mathrm{P}$ NMR spectra for KSW, KHW, and PHL lignins.

With the optimal conditions determined and the PHL lignin quality demonstrated, it is time to investigate the mass balance for the proposed process. Figure 13 shows the mass distribution of different pre-hydrolysate components in the feed, retentate, permeate, and filtrate obtained using the nanofiltration and precipitation of lignin from the prehydrolysate. It can be seen that, while most of acetic acid and formic acid ended up in the 
permeate during the nanofiltration step, most of the lignin and sugars were maintained by the membrane in the retentate. However, it seems that small amounts of lignin and sugars were lost in this step. This is due to the losses of retentate in the system tubing (an amount of the retentate remained in the piping and tubing of the nanofiltration system). This problem can be easily overcome at the industrial level by adopting a continuous membrane filtration system.

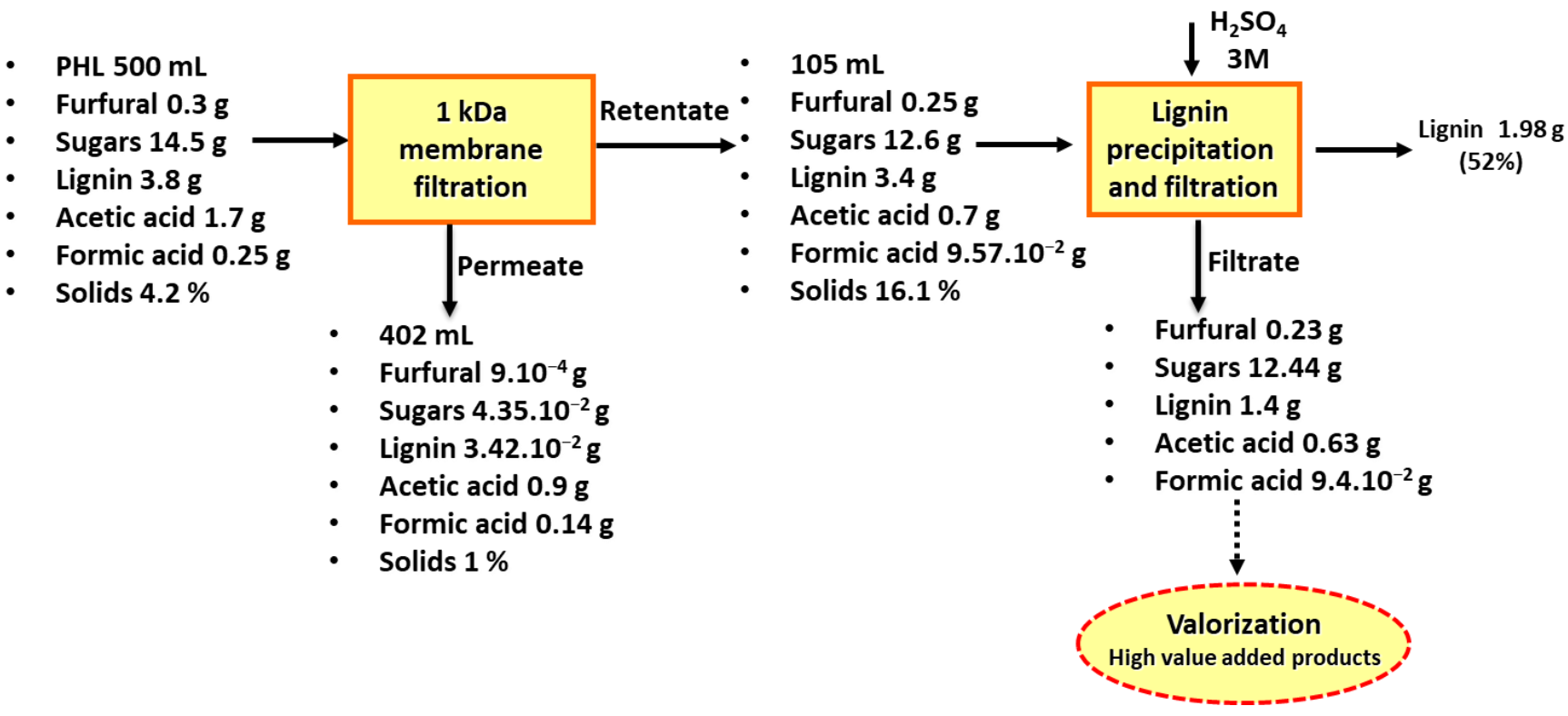

Figure 13. Mass balance for the proposed process.

The filtrate obtained after precipitating and recovering lignin (52\% of the initial lignin) contains most of chemical products present in the retentate. A valorization step is encouraged to diversify the portfolio of the pulp mill. Since it already contains sulfuric acid (resulting from the lignin precipitation step), a chemical conversion of sugars into a wide range of bioproducts such as furfural and hydroxymethylfurfural could be the most adapted for this case. The best way to valorize the resulting solution (residue) is by sending it to the recovery cycle because it contains the remaining organic bioproducts and lignin. The latter has a high calorific value and could be burned in the recovery boiler to produce energy.

For the permeate, the use of ion-exchange resin technology might remove the acetic acid and then the water obtained can be reused in the pre-hydrolysis step.

Lignin is a complex and three-dimensional macromolecule. This usually leads to a nonuniform reaction with other reagents. In fact, only functional groups at the surface of lignin can be easily reached. In addition to the problems related to the high diversity of its structure, lignin also has another issue of high importance. This issue is the large distribution of its molecular weight. Lignin is a very heterogeneous molecule [32-35]. In the same sample of lignin, the molecular weight of molecules of lignin can change significantly [30]. This makes its marketing a difficult task [32,35] and its use in some industrial applications a problematic issue $[32,34,36]$. Thus, the structure, the reactivity, the polydispersity, and thermal properties of lignin change according to its molecular weight. Morck et al. [37] and Thring et al. [38] reported that lignin fractions with a low molecular weight have good homogeneity and high guaiacyl content compared to lignin fractions with high molecular weight. Saito et al. [35] found that the glass transition temperature of lignin increases with its molecular weight. The same observations were reported by Yoshida et al. [39] and Morck et al. [37]. Therefore, lignin fractionation is one of the approaches to take into consideration in order to obtain lignins with well-defined properties [32]. In general, there are three methods of lignin fractionation: membrane separation by ultrafiltration [32,40-43], 
extraction by selective solvents [33], and precipitation by a gradual decrease in the $\mathrm{pH}$ of the solution [32].

Depolymerization is also one of the most studied techniques that are used in order to obtain a specific type of lignin. It reduces the molecular weight of lignin and leads to the de-methylation of some methoxyl groups [44,45]. This reduces its steric hindrance effects and improves its reactivity [45-47]. Ahmad et al., [48] reported obtaining lignin fractions of $2340 \mathrm{~g} \cdot \mathrm{mol}^{-1}$ after depolymerizing kraft lignin with a molecular weight of $10,000 \mathrm{~g} \cdot \mathrm{mol}^{-1}$. These results are consistent with those published by Yuan et al. [49] in which the molecular weight of a $\mathrm{kraft}$ lignin was reduced from $10200 \mathrm{~g} \cdot \mathrm{mol}^{-1}$ to $1020 \mathrm{~g} \cdot \mathrm{mol}^{-1}$ using reductive depolymerization in supercritical acetone. However, taking into account the size of investments required to depolymerize the lignin (high temperature, high pressure, use of solvents and other chemicals, and additional units for depolymerization), a very high yield would be highly desirable to make the process economically viable. The same thing can be said when it comes to ultrafiltration. On the other hand, the pre-hydrolysate lignin extracted in this work has a very low molecular weight $\left(1270 \mathrm{~g} \cdot \mathrm{mol}^{-1}\right)$, a high homogeneity $(\mathrm{Mw} / \mathrm{Mn}=1.22)$, and a low percentage of impurities. It is expected to be suitable for several applications (antioxidant or antiozonant in the plastic and polymer industry) without any additional treatment of fractionation, polymerization, or chemical modification.

\section{Conclusions}

The pre-hydrolysate generated at kraft dissolving pulp mills usually contains significant amounts of lignin. During lignin precipitation from the pre-hydrolysate, parameters such as filtration rate, coagulation time, sugars concentration, mineral element concentration, lignin purity, and molecular weight distribution are very important. The prehydrolysate must be first concentrated to increase the solid content. This study showed that a temperature of $40{ }^{\circ} \mathrm{C}$, a coagulation time of $180 \mathrm{~min}$, and a sulfuric acid concentration of $8.5 \mathrm{~kg} \cdot \mathrm{m}^{-3}$ are the optimal conditions to maximize lignin recovery from the pre-hydrolysate. About $52 \%$ of the initial lignin can be recovered, with a low content of impurities in the lignin cake (8.3\%). Compared to hardwood kraft lignin, the lignin precipitated from pre-hydrolysate is favored by having a low molecular distribution (1270 Da) and a very high homogeneity $(\mathrm{Mw} / \mathrm{Mn}=1.22)$. This lignin is considered a suitable feedstock for niche applications.

\section{Patents}

There is a patent [50] resulting from the work reported in this manuscript and from a work reported in some manuscripts already published $[7,11,18,51]$.

Author Contributions: Conceptualization, A.M., N.J., and W.W.A.D.; methodology, A.M., N.J., and W.W.A.D.; validation, A.M.; formal analysis, A.M.; investigation, A.M.; resources, M.P., M.M., and N.J.; data curation, A.M.; writing—original draft preparation, A.M.; writing—review and editing, N.J., W.W.A.D., M.P., and M.M.; visualization, A.M.; supervision, N.J., M.M., and M.P.; project administration, N.J.; funding acquisition, M.P. and M.M. All authors have read and agreed to the published version of the manuscript.

Funding: This research was funded by "Fonds de Recherche Nature et Technologie", "Conseil de Recherches en Sciences Naturelles et en Génie du Canada", and "FPInnovations".

Institutional Review Board Statement: Not applicable.

Informed Consent Statement: Not applicable.

Data Availability Statement: Data is contained within the article.

Conflicts of Interest: The authors declare no conflict of interest.

\section{References}

1. Macdonald, C. Dissolving pulp draws renewed interest. Pulp Pap. Can. 2011, 112, 19-26. 
2. Huang. S. Reductive Depolymerization of Kraft Lignin for Chemicals and Fuels Using Formic Acid as an In-Situ Hydrogen Source. Master's Thesis, University of Western Ontario, London, ON, Canada, 2014; p. 2.

3. Tran, H.N.; Elliott, M.; Barham, D.; Reeve, D. Recovery boiler operation and plugging in Canada. Pulp Pap. Can. 1986, 87, 58-64.

4. Kouisni, L.; Paleologou, M. Method for Separating Lignin from Black Liquor. U.S. Patent No. 8,940,130. U.S. Patent and Trademark Office: Washington, DC, USA, 9 April 2015.

5. Kouisni, L.; Holt-Hindle, P.; Maki, K.; Paleologou, M. The Lignoforce system: A new process for the production of high quality lignin from black liquor. J. Sci. Tech. Forest Prod. Proc. 2012, 2, 6-10.

6. Ohman, F.; Theliander, H.; Tomani, P.; Axegard, P. Method for Separating Lignin from Black Liquor. International Patent Application, WO2006/031175 A1, 23 March 2006.

7. Mazar, A.; Jemaa, N.; Al Dajani, W.W.; Marinova, M.; Perrier, M. Furfural production from a pre-hydrolysate generated using aspen and maple chips. Biomass Bioenergy 2017, 104, 8-16. [CrossRef]

8. Liu, H.; Hu, H.; Jahan, M.S.; Ni, Y. Improvement of Furfural Production from Concentrated PreHydrolysis Liquor (PHL) of a Kraft-Based Hardwood Dissolving Pulp Production Process. J. Wood Chem. Technol. 2015, 35, 260-269. [CrossRef]

9. Liu, H.; Hu, H.; Jahan, M.S.; Ni, Y. Furfural formation from the pre-hydrolysis liquor of a hardwood kraft-based dissolving pulp production process. Bioresour. Technol. 2013, 131, 315-320. [CrossRef]

10. Baktash, M.M.; Ahsan, L.; Ni, Y. Production of furfural from an industrial pre-hydrolysis liquor. Sep. Purif. Technol. 2015, 149, 407-412. [CrossRef]

11. Mazar, A.; Jemaa, N.; Al Dajani, W.W.; Marinova, M.; Perrier, M. Comparative study: Furfural production from two types of pre-hydrolysates produced using aspen and maple chips. Biomass Bioenergy 2018, 111, 103-113. [CrossRef]

12. Jahan, M.S.; Liu, Z.; Wang, H.; Saeed, A.; Ni, Y. Isolation and characterization of lignin from prehydrolysis liquor of kraft-based dissolving pulp production. Cellul. Chem. Technol. 2012, 46, 261-267.

13. Shi, H.; Fatehi, P.; Xiao, H.; Ni, Y. A combined acidification/PEO flocculation process to improve the lignin removal from the pre-hydrolysis liquor of kraft-based dissolving pulp production process. Bioresour. Technol. 2011, 102, 5177-5182. [CrossRef]

14. Yasarla, L.R.; Ramarao, B.V. Dynamics of Flocculation of Lignocellulosic Hydrolyzates by Polymers. Ind. Eng. Chem. Res. 2012, 51, 6847-6861. [CrossRef]

15. Shi, H.; Fatehi, P.; Xiao, H.; Ni, Y. A process for isolating lignin of pre-hydrolysis liquor of kraft pulping process based on surfactant and calcium oxide treatments. Biochem. Eng. J. 2012, 68, 19-24. [CrossRef]

16. Wang, Q.; Jahan, M.S.; Liu, S.; Miao, Q.; Ni, Y. Lignin removal enhancement from prehydrolysis liquor of kraft-based dissolving pulp production by laccase-induced polymerization. Bioresour. Technol. 2014, 164, 380-385. [CrossRef]

17. Wang, Q.; Liu, S.; Yang, G.; Chen, J. Modeling laccase-induced lignin removal in prehydrolysis liquor from kraft-based dissolving pulp production. Bioresour. Technol. 2015, 175, 638-641. [CrossRef] [PubMed]

18. Mazar, A.; Jemaa, N.; Al Dajani, W.W.; Marinova, M.; Perrier, M. Influence of membrane filtration on extraction and characteristics of lignin from a kraft dissolving pulp mill pre-hydrolysate. Ind. Crop. Prod. 2018, 124, 726-734. [CrossRef]

19. Ajao, O.; Le Hir, M.; Rahni, M.; Marinova, M.; Chadjaa, H.; Savadogo, O. Concentration and Detoxification of Kraft Prehydrolysate by Combining Nanofiltration with Flocculation. Ind. Eng. Chem. Res. 2015, 54, 1113-1122. [CrossRef]

20. Tavares, L.B.; Boas, C.V.; Schleder, G.R.; Nacas, A.M.; Rosa, D.S.; Santos, D.J. Bio-based polyurethane prepared from Kraft lignin and modified castor oil. Express Polym. Lett. 2016, 10, 927-940. [CrossRef]

21. Gómez-Fernández, S.; Ugarte, L.; Calvo-Correas, T.; Peña-Rodríguez, C.; Corcuera, M.A.; Eceiza, A. Properties of flexible polyurethane foams containing isocyanate functionalized kraft lignin. Ind. Crop. Prod. 2017, 100, 51-64. [CrossRef]

22. Solt, P.; Rößiger, B.; Konnerth, J.; Van Herwijnen, H.W. Lignin phenol formaldehyde resoles using base-catalysed de-polymerized Kraft lignin. Polymers 2018, 10, 1162. [CrossRef]

23. Brazil, T.R.; Gonçalves, M.; Junior, M.S.; Rezende, M.C. A statistical approach to optimize the activated carbon pro-duction from Kraft lignin based on conventional and microwave processes. Micropor. Mesopor. Mat. 2020, 308, 110485. [CrossRef]

24. Lourençon, T.V.; De Lima, G.G.; Ribeiro, C.S.; Hansel, F.A.; Maciel, G.M.; Da Silva, K.; Winnischofer, S.M.; De Muniz, G.I.; Magalhães, W.L. Antioxidant, antibacterial and antitumoural activities of kraft lignin from hardwood fractionated by acid precipitation. Int. J. Biol. Macromol. 2021, 166, 1535-1542. [CrossRef] [PubMed]

25. Shi, H.; Fatehi, P.; Xiao, H.; Ni, Y. Optimizing the poly ethylene oxide flocculation process for isolating lignin of prehy-drolysis liquor of a kraft-based dissolving pulp production process. Ind. Eng. Chem. Res. 2012, 51, 5330-5335. [CrossRef]

26. Chen, X.; Wang, Z.; Fu, Y.; Li, Z.; Qin, M. Specific lignin precipitation for oligosaccharides recovery from hot water wood extract. Bioresour. Technol. 2014, 152, 31-37. [CrossRef] [PubMed]

27. Norgren, M.; Edlund, H.; Wågberg, L.; Lindström, B.; Annergren, G. Aggregation of kraft lignin derivatives under con-ditions relevant to the process, part I: Phase behaviour. Colloids Surf. A 2001, 194, 85-96. [CrossRef]

28. Öhman, F.; Theliander, H. Filtration properties of lignin precipitated from black liquor. TAPPI J. 2007, 6, 3-9.

29. Faix, O. Classification of Lignins from Different Botanical Origins by FT-IR Spectroscopy. Holzforschung 1991, 45, 21-28. [CrossRef]

30. Gomez-Serrano, V.; Pastor-Villegas, J.; Perez-Florindo, A.; Duran-Valle, C.; Valenzuela-Calahorro, C. FT-IR study of rockrose and of char and activated carbon. J. Anal. Appl. Pyrolysis 1996, 36, 71-80. [CrossRef]

31. Li, B.; Zhou, M.; Huo, W.; Cai, D.; Qin, P.; Cao, H.; Tan, T. Fractionation and oxypropylation of corn-stover lignin for the production of biobased rigid polyurethane foam. Ind. Crop. Prod. 2020, 143, 111887. [CrossRef] 
32. Toledano, A.; García, A.; Mondragon, I.; Labidi, J. Lignin separation and fractionation by ultrafiltration. Sep. Purif. Technol. 2010, 71, 38-43. [CrossRef]

33. Yuan, T.-Q.; He, J.; Xu, F.; Sun, R. Fractionation and physico-chemical analysis of degraded lignins from the black liquor of Eucalyptus pellita KP-AQ pulping. Polym. Degrad. Stab. 2009, 94, 1142-1150. [CrossRef]

34. Sun, R.; Tomkinson, J. Fractional separation and physico-chemical analysis of lignins from the black liquor of oil palm trunk fibre pulping. Sep. Purif. Technol. 2001, 24, 529-539. [CrossRef]

35. Saito, T.; Perkins, J.H.; Vautard, F.; Meyer, H.M.; Messman, J.M.; Tolnai, B.; Naskar, A.K. Methanol Fractionation of Softwood Kraft Lignin: Impact on the Lignin Properties. ChemSusChem 2014, 7, 221-228. [CrossRef] [PubMed]

36. Brodin, I.; Sjöholm, E.; Gellerstedt, G. Kraft lignin as feedstock for chemical products: The effects of membrane filtration. Holzforschung 2009, 63, 290-297. [CrossRef]

37. Mörck, R.; Reimann, A.; Kringstad, K.P. Fractionation of kraft lignin by successive extraction with organic solvents: Functional groups, 13C NMR spectra and molecular weight distributions. Holzforschung 1986, 40, 51-60.

38. Thring, R.; Vanderlaan, M.; Griffin, S. Fractionation of Alcell ${ }^{\circledR}$ Lignin by Sequential Solvent Extraction. J. Wood Chem. Technol. 1996, 16, 139-154. [CrossRef]

39. Yoshida, H.; Mörck, R.; Kringstad, K.P.; Hatakeyama, H. Fractionation of kraft lignin by successive extraction with or-ganic solvents. II. Thermal properties of kraft lignin fractions. Holzforschung 1987, 41, 171-176. [CrossRef]

40. Wallberg, O.; Jönsson, A.S.; Wimmerstedt, R. Fractionation and concentration of kraft black liquor lignin with ultrafil-tration. Desalination 2003, 154, 187-199. [CrossRef]

41. Jönsson, A.-S.; Nordin, A.-K.; Wallberg, O. Concentration and purification of lignin in hardwood kraft pulping liquor by ultrafiltration and nanofiltration. Chem. Eng. Res. Des. 2008, 86, 1271-1280. [CrossRef]

42. Norgren, M.; Lindström, B. Physico-chemical characterization of a fractionated kraft lignin. Holzforschung 2000, 54, 528-534. [CrossRef]

43. Helander, M. The Use of Membrane Filtration to Improve the Properties of Extracted Wood Componets. Ph.D. Thesis, KTH Royal Institute of Technology, Stockholm, Sweden, 2014.

44. Beauchet, R.; Monteil-Rivera, F.; Lavoie, J.-M. Conversion of lignin to aromatic-based chemicals (L-chems) and biofuels (L-fuels). Bioresour. Technol. 2012, 121, 328-334. [CrossRef]

45. Diop, A. Extraction, Dépolymérisation et Valorisation de la Lignine Kraft de la Liqueur Noire. Ph.D. Thesis, Sciences et Génie des Matériaux Lignocellulosiques, Université de Québec à Trois Rivières, Trois-Rivières, QC, Canada, 2014.

46. Madhav, P.P. Lignin Depolymerisation and Conversion: A Review of Thermochemical Methods. Chem. Eng. Technol. 2011, $34,29-41$.

47. Khitrin, K.S.; Fuks, S.L.; Khitrin, S.V.; Kazienkov, S.A.; Meteleva, D.S. Lignin utilization options and methods. Russ. J. Gen. Chem. 2012, 82, 977-984. [CrossRef]

48. Ahmad, Z.; Mahmood, N.; Yuan, Z.; Paleologou, M.; Xu, C.C. Effects of Process Parameters on Hydrolytic Treatment of Black Liquor for the Production of Low-Molecular-Weight Depolymerized Kraft Lignin. Molecules 2018, 23, 2464. [CrossRef]

49. Yuan, Z.; Tymchyshyn, M.; Xu, C. (Charles) Reductive Depolymerization of Kraft and Organosolv Lignin in Supercritical Acetone for Chemicals and Materials. ChemCatChem 2016, 8, 1968-1976. [CrossRef]

50. Jemaa, N.; Mazar, A.; AL DAJANI, W.W.; Paleologou, M. Lignin Recovery and Furfural Production from Prehydrolysate Streams. U.S. Patent Application No.16/088,980, October 15, 2020.

51. Mazar, A.; Ajao, O.; Benali, M.; Jemaa, N.; Al-Dajani, W.W.; Paleologou, M. Integrated Multiproduct Biorefinery for Furfural Production with Acetic Acid and Lignin Recovery: Design, Scale-Up Evaluation, and Technoeconomic Analysis. ACS Sustain. Chem. Eng. 2020, 8, 17345-17358. [CrossRef] 